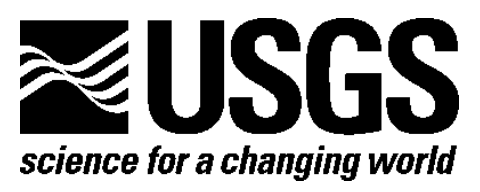

Prepared in cooperation with the U.S. Environmental Protection Agency

\title{
An Evaluation of Remote Sensing Technologies for the Detection of Residual Contamination at Ready-for- Anticipated Use Sites
}

By E. Terrence Slonecker and Gary B. Fisher

Open-File Report 2014-1197

U.S. Department of the Interior

U.S. Geological Survey 


\section{U.S. Department of the Interior \\ SALLY JEWELL, Secretary}

\section{U.S. Geological Survey \\ Suzette M. Kimball, Acting Director}

U.S. Geological Survey, Reston, Virginia: 2014

For more information on the USGS—-the Federal source for science about the Earth,

its natural and living resources, natural hazards, and the environment-visit

http://www.usgs.gov or call 1-888-ASK-USGS (1-888-275-8747)

For an overview of USGS information products, including maps, imagery, and publications, visit http://www.usgs.gov/pubprod

To order this and other USGS information products, visit http://store.usgs.gov

Any use of trade, firm, or product names is for descriptive purposes only and does not imply endorsement by the U.S. Government.

Although this information product, for the most part, is in the public domain, it also may contain copyrighted materials as noted in the text. Permission to reproduce copyrighted items must be secured from the copyright owner.

Suggested citation:

Slonecker, E.T., and Fisher, G.B., 2014, An Evaluation of remote sensing technologies for the detection of residual contamination at Ready-for-Anticipated Use sites: U.S. Geological Survey Open-File Report 2014-1197, 25 p., http://dx.doi.org/10.3133/ofr20141197.

ISSN 2331-1258 (online) 


\section{Contents}

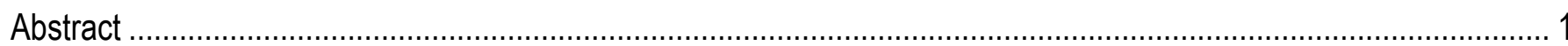

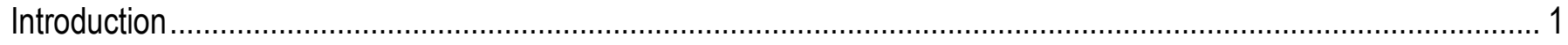

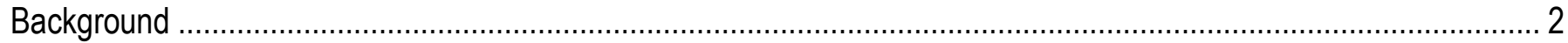

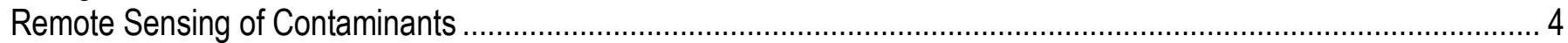

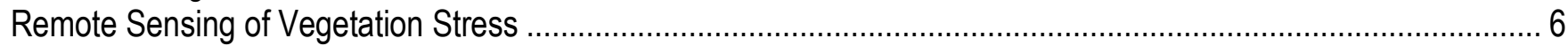

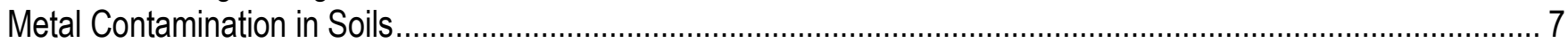

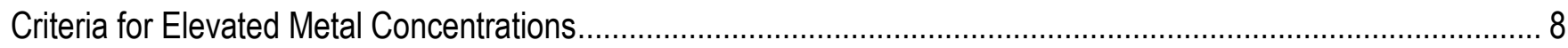

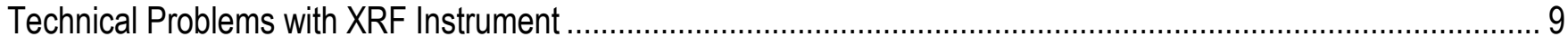

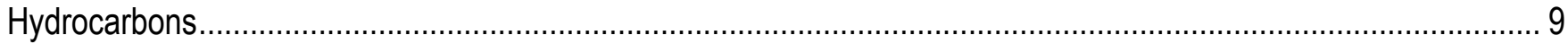

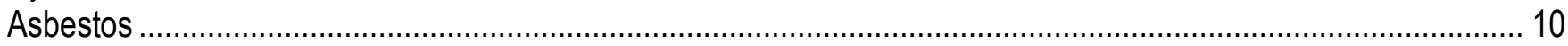

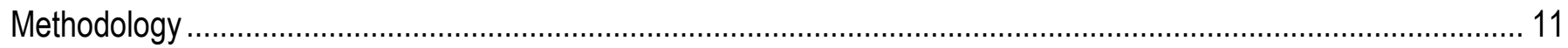

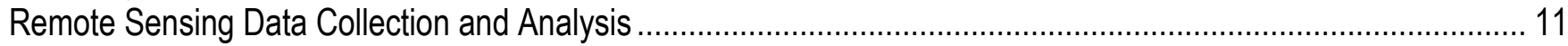

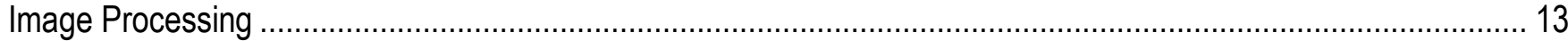

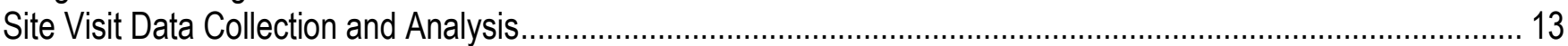

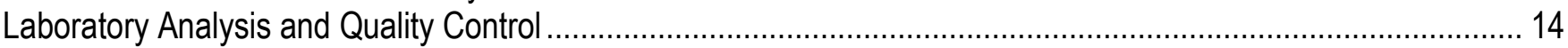

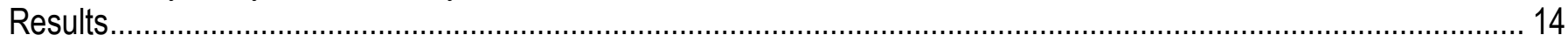

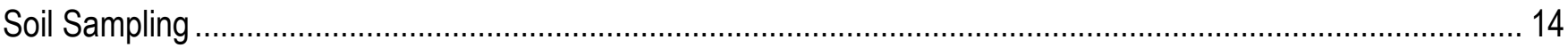

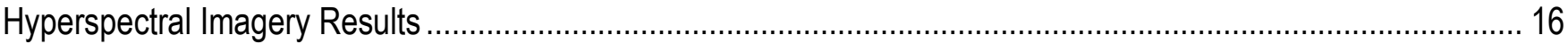

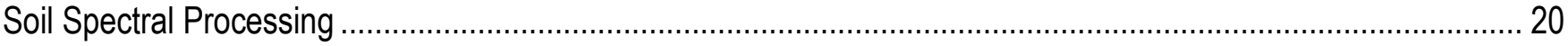

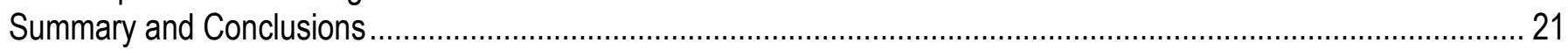

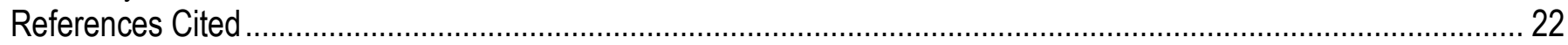

\section{Figures}

1. Locations of the 24 sites in this study in Florida, Louisiana, South Carolina, and Texas .............................

2. Hyperspectral images are collections of hundreds of bands of coregistered imagery ................................5

3. Hyperspectral Concept .......................................................................................................

4. Spectra of typical hydrocarbon absorption features occurring at or near 1,$200 ; 1,730$; and $2,310 \mathrm{~nm} \ldots \ldots . .10$

5. Asbestos minerals, such as tremolite, have distinctive absorption features at or near 1,385 and

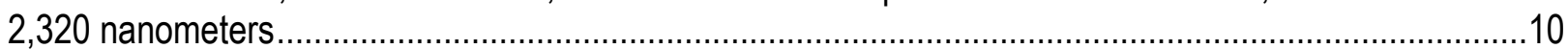

6. The combined hyperspectral techniques used in this report.........................................................12

7. The solar-reflected electromagnetic spectrum coverage of the Civil Air Patrol's Airborne Real-

Time Cueing Hyperspectral Enhanced Reconnaissance system and Analytical Spectral Devices

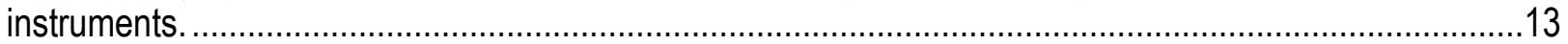

8. Soil sampling and field X-ray fluorescence screening.....................................................................

9. Sampling locations at the Cadiz Street Site in, Dallas, Texas.............................................................15

10. ARCHER Hyperspectral Image Processing Results for 210 North 12th Street, Tampa, Florida.................17

11. ARCHER Hyperspectral Image Processing Results for the Encore Retail Site, in Tampa, Florida.............18

12. ARCHER Hyperspectral Image Processing Results for the Clearwater Auto Site, Clearwater, Florida ......19

13. ARCHER Hyperspectral Image Processing Results for the 22nd Street Mixed-Use Site ..........................20

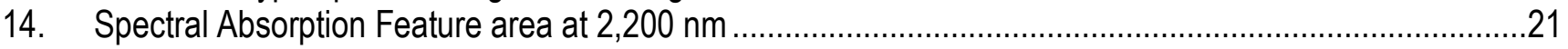




\section{Tables}

1. The sites sampled in this evaluation of remote sensing technologies for the detection of residual contamination in Florida (FL), Louisiana (LA), South Carolina (SC), and Texas (TX)...............................

2. State residential and industrial risk-based concentrations of selected metals. All values are in milligrams per kilogram.

3. Contaminants, stress, and spectral wavebands investigated in this study. 


\section{Conversion Factors}

Inch/Pound to International System of Units

\begin{tabular}{|c|c|c|}
\hline Multiply & By & To obtain \\
\hline \multicolumn{3}{|c|}{ Length } \\
\hline inch (in.) & 2.54 & centimeter $(\mathrm{cm})$ \\
\hline foot (ft) & 0.3048 & meter $(\mathrm{m})$ \\
\hline mile (mi) & 1.609 & kilometer (km) \\
\hline Millimeter (mm) & 0.03937 & Inch (in.) \\
\hline \multicolumn{3}{|c|}{ Area } \\
\hline acre & 4,047 & square meter $\left(\mathrm{m}^{2}\right)$ \\
\hline acre & 0.4047 & hectare (ha) \\
\hline
\end{tabular}

Horizontal coordinate information is referenced to the North American Datum of 1983 (NAD 83).

\section{Abbreviations}

ARCHER Airborne Real-Time Cueing Hyperspectral Enhanced Reconnaissance

AVIRIS Airborne Visible/Infrared Imaging Spectrometer

ASD Analytical Spectral Devices

CAP Civil Air Patrol

EMR electromagnetic radiation

EPA U.S. Environmental Protection Agency

HSI hyperspectral imagery

JPL Jet Propulsion Laboratory (National Aeronautics and Space Administration)

$\mathrm{mg} / \mathrm{kg} \quad$ milligrams per kilogram

NASA National Aeronautics and Space Administration

nm nanometer

OIG Office of Inspector General

OFR Open-File Report (U.S. Geological Survey)

LUE Light Use Efficiency

PRI photochemical reflectance index

RAU Ready-for-Anticipated Use

RCRA CA Resource Conservation and Recovery Act Corrective Action

USGS U.S. Geological Survey

XRF X-ray fluorescence 


\title{
An Evaluation of Remote Sensing Technologies for the Detection of Residual Contamination at Ready-for- Anticipated Use Sites
}

\author{
By E. Terrence Slonecker and Gary B. Fisher
}

\section{Abstract}

During 2013, 24 U.S. Environmental Protection Agency (EPA) Ready-for-Anticipated Use (RAU) sites in Florida, Louisiana, South Carolina, and Texas were imaged with an ARCHER hyperspectral imaging sensor and visited in the field for site inspection, screening, and collection of soil samples. Soil samples were screened in the field and later analyzed with a portable X-ray fluorescence (XRF) analyzer for metal content. Reflectance spectroscopic measurements were also made in the laboratory on each soil sample. Samples were analyzed for hydrocarbons, asbestos, and metal content. Hyperspectral images were processed and analyzed for vegetation stress correlated to heavy-metal contamination.

Operational problems with site access and information, XRF instrument operation, and imagery collections hampered the effective data collection and analysis process. Of the 24 sites imaged and analyzed, 17 appeared to be relatively clean with no discernible metal contamination, hydrocarbons, or asbestos in the soil. None of the samples for the sites in Louisiana had any result exceeding the appropriate industrial or residential standard for arsenic or lead. One site in South Carolina (North Street Dump) had two samples that exceeded the residential standard for lead. One site in Texas (Cadiz Street), and four sites in Florida (210 North 12th Street, Encore Retail Site, Clearwater Auto, and 22nd Street Mixed Use) were found to have some level of residual metal contamination above the applicable residential or commercial Risk-Based Concentration (RBC) standard. Three of the Florida sites showing metal contamination also showed a pattern of vegetation stress based on standard vegetation analysis techniques.

\section{Introduction}

This report describes a remote sensing research effort conducted by the U.S. Geological Survey (USGS) for the Office of Inspector General (OIG) of the U.S. Environmental Protection Agency (EPA). The objective of the research was to explore the efficacy of remote sensing as a technology for detecting residual contamination at sites within EPA's land cleanup programs that have been declared Ready-forAnticipated Use (RAU) as defined under the EPA's Cross-Program Revitalization Measures initiative.

The EPA Office of Solid Waste and Emergency Response developed the Cross-Program Revitalization Measures to define and communicate: (1) the amount of contaminated (or potentially contaminated) land EPA's cleanup programs address; (2) the progress of cleanup; and (3) the potential for reuse. The measures include sites in the Superfund, Brownfields, Resource Conservation and Recovery Act Corrective Action (RCRA CA), and other cleanup programs (U.S. Environmental Protection Agency, 2010). 


\section{Background}

In 2007, the EPA OIG issued an evaluation report "Limited Investigation Led to Missed Contamination at Ringwood Superfund Site" (U.S. Environmental Protection Agency, 2007). This report documented problems of insufficient characterization and cleanup. A key finding was that the failure to detect the extent of contamination might have been avoided if the EPA had made greater use of available aerial photographs. Morphological characteristics of the landscape and landscape changes, as documented in historical aerial imagery, could have been used to detect the much larger extent of paint sludge and contamination than was thought to exist after the initial remedial investigation (Baker, 1983; U.S. Environmental Protection Agency, 2007).

Based on the findings from the Ringwood investigation, the OIG initiated a series of research projects, in cooperation with the USGS, to evaluate the potential use of emerging remote sensing technology in monitoring conditions at RAU sites. The first projects (Slonecker and Fisher, 2011; Slonecker and Fisher, 2014) found that 6 of the 17 RAU Superfund sites evaluated had detectable postclosure issues with site activity, soil metals, site security, and onsite debris. In the research presented here, the evaluation is extended to other types of cleanup sites, including Brownfields and RCRA CA sites.

Twenty-four sites were investigated in Florida, Louisiana, South Carolina, and Texas in 2013 (table 1; fig. 1). Twenty-two of these sites had been declared RAU. All were imaged with an airborne hyperspectral sensor. All sites were visited for inspection of general site conditions and for the collection of soil samples. Samples were analyzed for metals and additional spectral measurements were made in the laboratory with a field-portable spectroradiometer.

Table 1. The sites sampled in this evaluation of remote sensing technologies for the detection of residual contamination in Florida (FL), Louisiana (LA), South Carolina (SC), and Texas (TX).

[LU, land use; R, residential; I, industrial; RAU, Ready for Anticipated Use; and RCRA CA, Resource Conservation and Recovery Act Corrective Action]

\begin{tabular}{|c|c|c|c|c|c|}
\hline Site Name & EPA-ID & Location & Program & $\begin{array}{l}\text { Industrial or } \\
\text { residential } \\
\text { LU }\end{array}$ & Comments \\
\hline 1. 210 North 12 th Street & & Tampa, FL & Brownfields & $\mathrm{R}$ & $\begin{array}{l}\text { Not RAU: Sampled empty } \\
\text { Non-RAU lot adjacent to } \\
\text { RAU Brownfields } \\
10042300890\end{array}$ \\
\hline 2. Encore Retail Site & 110044760210 & Tampa, FL & Brownfields & $\mathrm{R}$ & Not RAU \\
\hline 3. 22nd Street Mixed Use & 110038736687 & Tampa, FL & Brownfields & $\mathrm{R}$ & RAU \\
\hline 4. Blue Chip Bar & 110042300266 & Clearwater, FL & Brownfields & $\mathrm{R}$ & RAU \\
\hline 5. Clearwater Auto & 110038699281 & Clearwater, FL & Brownfields & $\mathrm{R}$ & RAU \\
\hline 6. Pro-Fit Development & 110039058890 & Tampa, FL & Brownfields & $\mathrm{R}$ & RAU \\
\hline 7. St. Vincent & 110042301265 & Clearwater, FL & Brownfields & $\mathrm{R}$ & RAU \\
\hline 8. 1705 Highland Road & 110039062493 & Baton Rouge, LA & Brownfields & $\mathrm{R}$ & RAU \\
\hline 9. 2750 Nicholson Drive & 110038693009 & Baton Rouge, LA & Brownfields & $\mathrm{R}$ & RAU \\
\hline 10. Former Juban Lumber & 110039062475 & Baton Rouge, LA & Brownfields & $\mathrm{R}$ & RAU \\
\hline 11. Marathon Petroleum & LAD081999724 & Garyville, LA & RCRA CA & I & RAU \\
\hline 12. Personal Touch Car Wash & 110042237406 & Baton Rouge, LA & Brownfields & $\mathrm{R}$ & RAU \\
\hline 13. Syngenta Crop Protection & LAD053783445 & St. Gabriel, LA & RCRA CA & I & RAU \\
\hline 14. 622/624 Green Avenue & 110042301595 & Greenville, SC & Brownfields & $\mathrm{R}$ & RAU \\
\hline 15. Arkwright Mills & 110038748889 & Spartanburg, SC & Brownfields & I & RAU \\
\hline 16. IWG Conductors & SCD061523098 & Inman, SC & RCRA CA & I & RAU \\
\hline
\end{tabular}


Table 1. The sites sampled in this evaluation of remote sensing technologies for the detection of residual contamination in Florida (FL), Louisiana (LA), South Carolina (SC), and Texas (TX).- Continued

[LU, land use; R, residential; I, industrial; RAU, Ready for Anticipated Use; and RCRA CA, Resource Conservation and Recovery Act Corrective Action]

\begin{tabular}{llllll}
\hline \multicolumn{1}{c}{ Site Name } & \multicolumn{1}{c}{ EPA-ID } & \multicolumn{1}{c}{ Location } & Program & $\begin{array}{c}\text { Industrial or } \\
\text { residential } \\
\text { LU }\end{array}$ & Comments \\
\hline 17. North Street Dump & 110038748442 & Spartanburg, SC & Brownfields & I & RAU \\
18. Taylor Street & 110040129223 & Columbia, SC & Brownfields & R & RAU \\
19. Roy Metals & SCD003341849 & Conestee, SC & RCRA CA & I & RAU \\
20. Union Mill & 110002231790 & Union, SC & Brownfields & I & RAU \\
21. Cadiz Street & 110038735820 & Dallas, TX & Brownfields & I & RAU \\
22. Former Trans Maintenance & 110039059853 & Arlington, TX & Brownfields & I & RAU \\
23. Joint Reserve Base & TX0571924042 & Forth Worth, TX & RCRA CA & I & RAU \\
24. Sheppard AFB & TX3571524161 & Wichita Falls, TX & RCRA CA & I & RAU \\
\hline
\end{tabular}
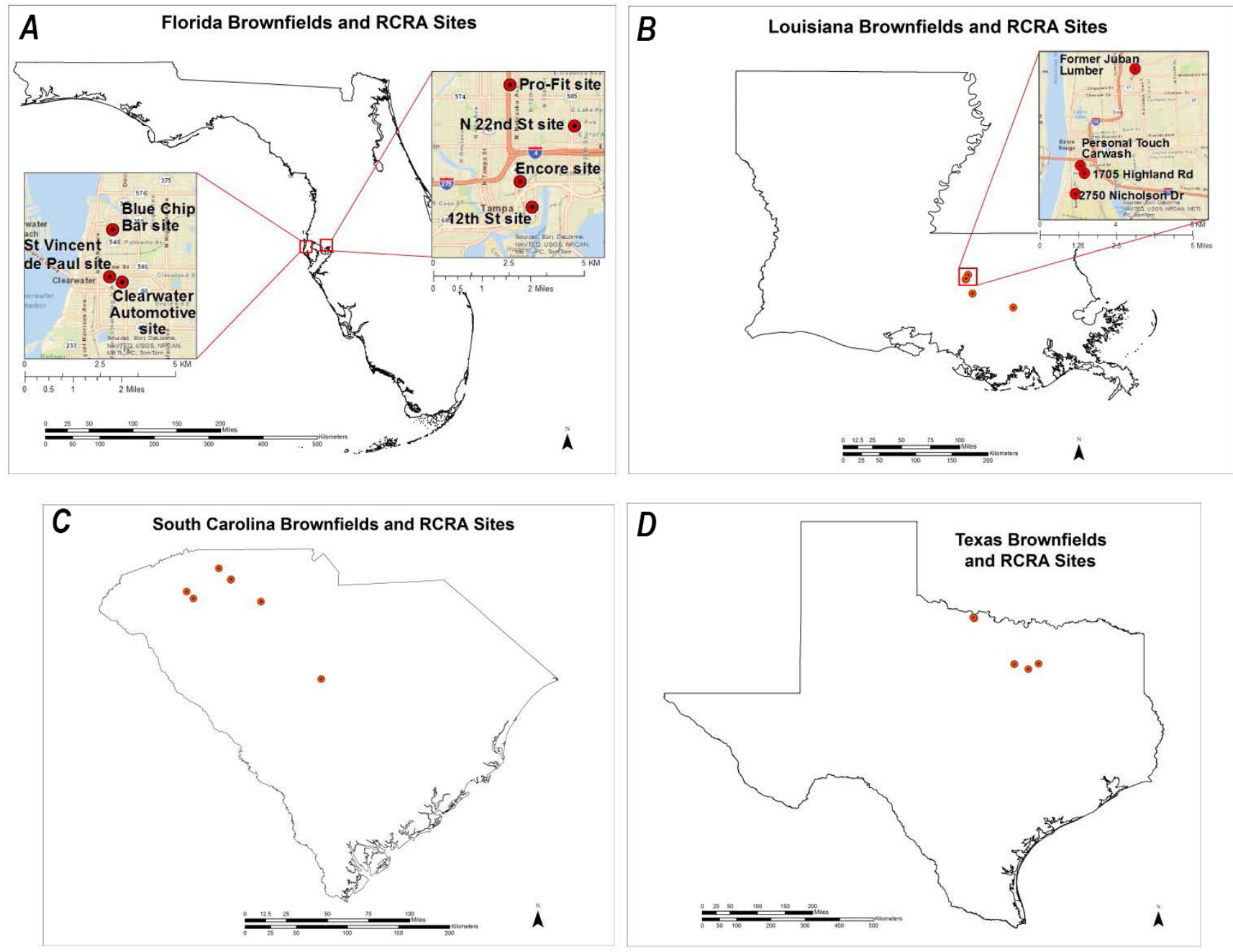

Figure 1. Locations of the 24 sites in this study in Florida, Louisiana, South Carolina, and Texas. 


\section{Remote Sensing of Contaminants}

Remote sensing is becoming an increasingly important science for advancing understanding of environmental processes, conditions, and changes for both human and ecological health. Major advancements in sensor technology and processing algorithms have resulted in technical capabilities that can record and identify earth surface materials based on the interaction of electromagnetic energy with the molecular structure of the material being sensed (Goetz and others, 1985; Green and others, 1998; Clark, 1999; Clark and others, 2009). Hyperspectral remote sensing records reflected and emitted electromagnetic energy in hundreds of very narrow wavelengths. This results in data for a particular location that can be analyzed with the same spectroscopic techniques that have been used by chemists and astronomers for over a century. In addition, new analytical techniques are being developed and refined that permit the identification and analysis of key environmental processes, such as photosynthesis and nutrient cycling, which are important for the detection of anthropogenic stress that might be caused by soil or groundwater contamination.

Spectral reflectance of vegetation and other landscape conditions has received renewed interest by the remote sensing community during the past decade because of the development of this new class of imaging technology. Many of the early and definitive studies in spectral reflectance utilized spectroscopic measurement instruments in a laboratory setting (Horler and others, 1980; Chang and Collins, 1983; Milton and others, 1989). These instruments measured reflected energy and produced spectra that could be analyzed using standard spectral analysis techniques.

Spectroscopic analysis techniques can be employed now outside of the laboratory through the use of hyperspectral remote sensing-imaging techniques and portable field spectroradiometers. The geospatial collection of coregistered hyperspectral imagery in very narrow bandwidths across the solar-reflected part of the electromagnetic spectrum (from 400 to 2,500 nm) results in what is often called an "image cube" (see fig. 2). After processing, the image cube represents an imagery version of the same energy and matter interactions measured in the laboratory. The image cube can be analyzed with a variety of standard and emerging statistical methods in spectroscopy, signal processing, and remote sensing. Reflectance spectra can be used to identify certain compounds, materials, and their conditions based on the interaction of photons of light with the molecular structure of the target material (Vane and Goetz, 1988; Green and others, 1998; Clark, 1999) (see fig. 3). This research seeks to evaluate traditional and hyperspectral imagery and field spectroscopic measurement techniques in the characterization and analysis of residual contamination at sites that have been declared ready for anticipated use. 


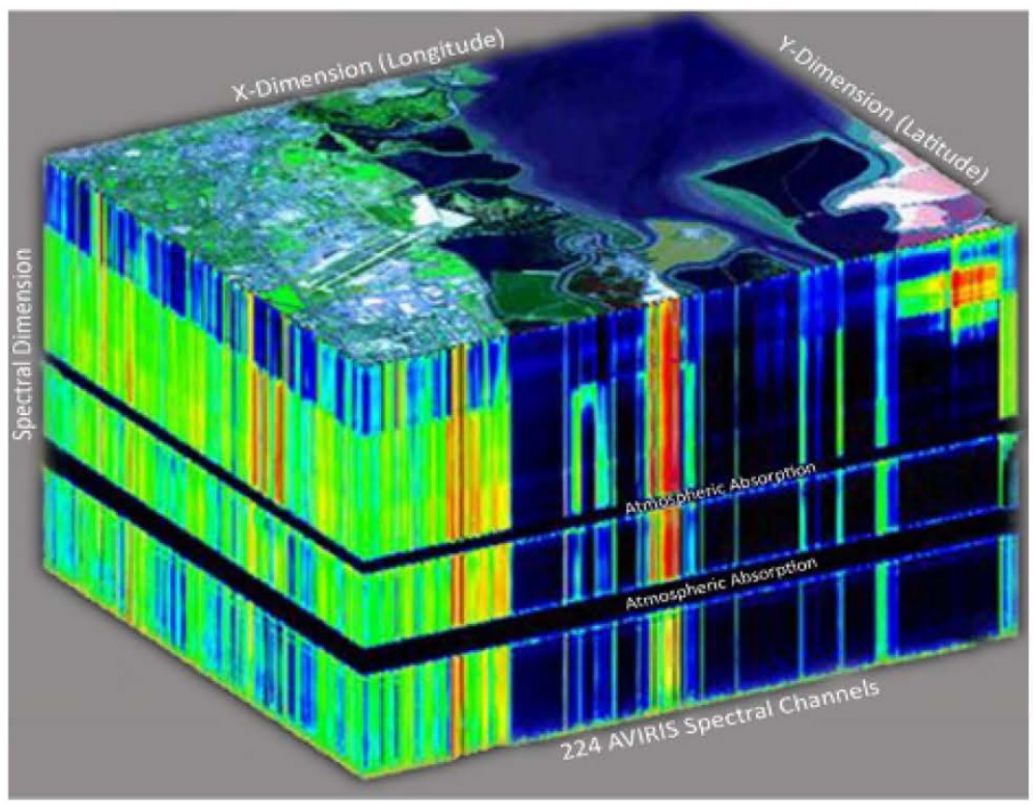

Figure 2. Hyperspectral images are collections of hundreds of bands of coregistered imagery. Each band collects reflected energy in a slightly different wavelength location. Assembled together geospatially results in what is often called an "image cube." The image shown here, of Moffett Field, California, was collected on August 20, 1992, from a height of 20,000 meters. [Image from the National Aeronautics and Space Administration Jet Propulsion LaboratoryAirborne Visible/Infrared Imaging Spectrometer Web site (http://aviris.jpl.nasa.gov/html/aviris.cube.html)] (National Aeronautics and Space Administration, 2010).

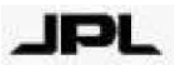

\section{AVIRIS CONCEPT}
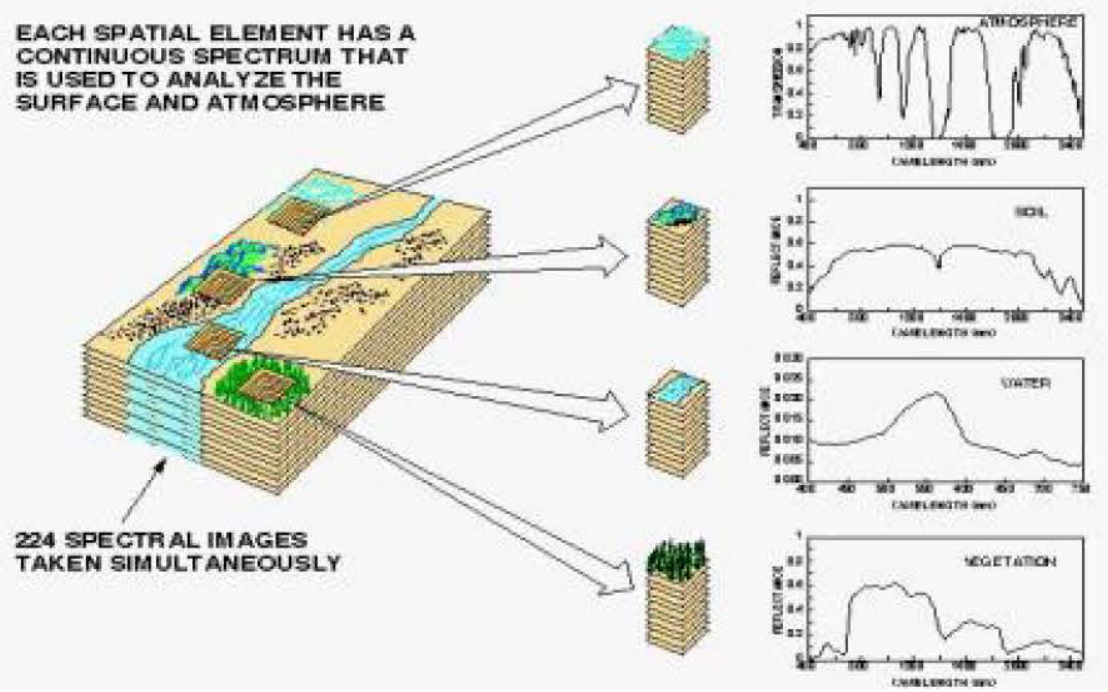

Figure 3. Hyperspectral Concept. When processed, the image cube can be analyzed with conventional spectroscopic analysis methods-hence, the term "imaging spectroscopy." [Image from the National Aeronautics and Space Administration Jet Propulsion Laboratory, Visible/Infrared Imaging Spectrometer Web site (http://aviris.jpl.nasa.gov/html/aviris.concept.html)] (National Aeronautics and Space Administration, 2007). 


\section{Remote Sensing of Vegetation Stress}

A key aspect in the study of residual contaminants in the environment is the effect that contaminants have on cover vegetation. In most cases, soil or groundwater contaminants, such as hydrocarbons, heavy metals, and organic chemicals, will have negative effects on the metabolism and growth of typical cover vegetation, such as trees or grasses. Remote sensing of vegetation stress has been, and continues to be, a key aspect of remote sensing research.

As both spectroscopic and remote sensing research developed, specific patterns of vegetation stress began to emerge and spawned research in the 1990s. The shift in the "red edge" of vegetation reflectance, related to plant health and (or) stress, was identified and used in a number of research studies and is still used today in studying vegetation condition. A series of special spectral calculations called "hyperspectral vegetation indices" were developed to maximize and take advantage of high-spectral resolution and specific qualities of vegetation growth and health. These indices are derived from the spectral reflectance properties of vegetation and are designed to accentuate a specific property of vegetation, such as leaf moisture content. As remediated sites are likely to have been reclaimed or revegetated, vegetation indices are a key component of assessing residual surface contamination of these sites.

A key question in this and future hyperspectral research lies in the ability to detect and differentiate natural stress, such as drought, from anthropogenic stress, as might be caused by chemical contamination in the soil. Imaging spectroscopy of plant and tree health has been an important research area for some time, and recent research suggests that there are physiological and potential spectral distinctions between natural stress, such as drought, and anthropogenic stress, such as soil chemical contamination, due to different physiological responses of the plant (Zinnert and others, 2012). Further development of this capability would be an important aspect of hyperspectral research.

An example of a commonly used vegetation index is the photochemical reflectance index (PRI) that measures carotenoid pigments, and thus, light use efficiency (LUE) in plants, giving a measure of productivity and stress in the physiological status of the plant. PRI is computed from hyperspectral wavebands using the following formula:

$$
\text { PRI }=\frac{\text { W531 - W570 }}{\text { W531 + W570 }}
$$

where W531 and W570 are the spectral values at specific wavelengths in the reflected spectrum. Developed by Gamon and others $(1992,1997)$, this formula has proven successful at identifying subtle patterns of stress that could be caused by soil contamination. Although the PRI index is commonly used in vegetation stress scenarios, there are other indices that have been calculated and used effectively (Thenkabail and others, 2000).

Vegetation stress images used in this report were created using a standard agricultural stress tool in the Environment for Visualizing Images (ENVI). The agricultural stress tool evaluates the growth efficiency of low-level, nonforest vegetation. Very dry or dying vegetation does not efficiently utilize nitrogen and light, whereas healthy vegetation is actively involved in photosynthesis and shows little or no stress. This stress indicator uses a combination of specific vegetation indices, such as greenness, light-use efficiency, nitrogen, leaf pigments, and canopy water content. The agricultural stress index is designed to measure the health of low-level plants, such as crops, as opposed to forest health, which involves other parameters. The agricultural stress index divides the input scene into nine classes, from lowest stress (purple-blue) to highest stress (red-black). The classifications and colors are relative to the individual image. 


\section{Metal Contamination in Soils}

A primary concern at some RAU sites is residual metal contamination in the soil. Both the direct reflectance of metals in the soil matrix and the effect of metals on vegetation reflectance are potentially observable. Many naturally occurring metals are constituents of minerals and of the surficial properties of soils. In mineral form, such as galena (lead) and sphalerite (zinc), metals occur naturally throughout the Earth's crust and the natural level of metals in soil is called the background concentration. The background concentration of metals has been reported in the literature by comprehensive scientific studies based on regional sampling (Shacklette and Boerngen, 1984). The background of specific metals that are common contaminants was also reported in Slonecker and Fisher $(2011,2014)$. However, when mined for the specific metal or used in industrial processes, waste metals can be found in soils at concentrations that are orders of magnitude higher than natural concentrations and become risks to human and ecological health.

The identification of metals and metal concentrations in soils generally involves wet chemical acid digestion, using methods such as EPA Methods 3050 and 6010 for total metals. In recent years, X-ray fluorescence (XRF) methods (EPA Method 6200) have become accepted field methods for the screening of metals in soils. XRF methods were used primarily in this study and were verified with laboratory analysis (EPA 3050/EPA 6010) conducted on a subset of the samples (MACS Lab, 2013a).

All of the above-mentioned methods require the collection of samples and laboratory analysis or, in the case of XRF technology, physical contact with the soil. A sensing method that might identify soil contamination remotely could be a valuable new monitoring tool. Several studies have indicated the possibility of applying field and imaging spectroscopy in the identification of minerals containing heavy metals as an indicator of contamination in mining areas (Farrand and Harsanyi, 1997; Ferrier, 1999; Swayze and others, 2000). Montero and others (2005) assessed the potential of abandoned mines for acid mine drainage by characterizing waste rock associated with acid drainage using reflectance spectroscopy.

A key question revolves around the possibility of detecting metal contamination in soils by way of reflected electromagnetic energy that would enable laboratory or imaging spectroscopy. Most metals occur naturally in a mineral form and have been the subject of much research and characterization over the years (Clark and others, 2005). Large spectral libraries of mineral spectra, with characteristic absorption features, have been developed by USGS, the National Aeronautics and Space Administration, and others (Sheppard and Walsh, 2002; Clark and others, 1999; Baldridge and others, 2009). Minerals have common molecular structures that are conductive to distinctive energy absorptions that are displayed in the solarreflected part of the electromagnetic spectrum. Electronic transitions or vibrational effects in the molecular lattice structure often present distinctive signatures in the spectra of the materials (Clark and others, 1999).

When metals have been mined and extracted from their mineral form and are released into the environment in a pure, or different, chemical form, much less is understood about their spectral properties and the ability to detect them remotely. Although spectral patterns are not as well documented or understood as when the metals are not in mineral form, some progress has been made. Studies by Kemper and Sommer (2002), Choe and others (2008), and Pandit and others (2010) demonstrated that direct, stand-off detection (remote sensing and field spectroscopy) of high concentrations of metals in soils is possible. Wu and others (2007) showed using visible and near-infrared spectroscopy that reflectance responses and the concentrations of certain metals (arsenic, cadmium, chromium, copper, mercury, nickel, lead, and zinc) in contaminated soils were negatively correlated. Spectral features have been reported to be related to the level of metal contamination. These features include the band depth at 500;1,400;1,900; and 2,200 $\mathrm{nm}$; the ratio of bands at the wavelengths (in nm) 610/500 and 1,344/778; and the band depth and band feature area at 2,200 $\mathrm{nm}$ (Choe and others, 2008; Kemper and Sommers, 2002; Gannouni and others, 2012). In general, the level of metals in soils is related to other constituents of the soil matrix, such as iron or organic matter content (Ji and others, 2010). Wu and others (2007) concluded that most research 
to date detects the level of metals in soils by indirectly measuring the relationship with other soil parameters, such as iron, organic matter and clay content. Also, Wu and others (2007) showed that spectroscopic detection of metals in the soil matrix is difficult unless the concentration exceeds 1,000 milligrams per kilogram.

\section{Criteria for Elevated Metal Concentrations}

Heavy metals are contaminants of concern at most of the sites evaluated. The ability of remote sensing to detect metal concentrations in soils is an important aspect of this study. All soil samples collected at the sites were analyzed in the laboratory with an Analytical Spectral Devices (ASD) spectroradiometer. XRF technology was used to screen soil metals in the field and later in the laboratory to evaluate metals concentrations. The relation between reflectance and soil metal concentration was evaluated.

The risk-based concentration of individual contaminants is a screening level that is established by a State or Federal agency to determine when a site is initially investigated if potentially substantial levels of contamination are present to warrant further investigation. Risk-based concentrations are a complex calculation of toxicity, exposure, and carcinogenic probabilities. They are applied to contaminant concentrations at a site according to anticipated land use and exposure scenarios, whether residential or industrial. Some States, such as Florida, Louisiana, and Texas, have developed their own screening levels (Florida Department of Environmental Protection, 2005; Louisiana Department of Environmental Quality, 2003; Texas Commission on Environmental Quality, 2006). Others, such as South Carolina, have not. EPA developed screening levels that can be used for sites where the State has not established their own (U.S. Environmental Protection Agency, 2013). Table 2 shows the risk-based concentrations for selected metals by State. For this research the laboratory results were compared against appropriate screening levels to determine sites that had possible residual soil contamination. The general land use surrounding the site was used to determine the appropriate screening level. While this may be debatable based on zoning classifications, the exposure scenario appeared to be primarily residential at most of the sites, and absent any clear evidence of industrial land use, the residential standard was used for reporting. The EPA national risk-based concentrations for residential and industrial soil contaminants can be found in the References Cited section (U.S. Environmental Protection Agency, 2013). In the References Cited section, State standard can be found for Florida (Florida Department of Environmental Protection, 2005); for Louisiana (Louisiana Department of Environmental Quality, 2003); and for Texas (Texas Commission on Environmental Quality, 2006).

Table 2. State residential and industrial risk-based concentrations of selected metals. All values are in milligrams per kilogram.

\begin{tabular}{lcccc}
\hline \multicolumn{1}{c}{ Metal } & $\begin{array}{c}\text { Florida } \\
\text { Residential }\end{array}$ & Florida Industrial & $\begin{array}{c}\text { Louisiana } \\
\text { Residential }\end{array}$ & $\begin{array}{c}\text { Louisiana } \\
\text { Industrial }\end{array}$ \\
\hline Arsenic & 2.1 & 12 & 12 & 12 \\
Cadmium & 82 & 1,700 & 3.9 & 100 \\
Copper & 150 & 89,000 & 310 & 8,200 \\
Lead & 400 & 1,400 & 400 & 1,400 \\
Nickel & 340 & 35,000 & 160 & 4,100 \\
Zinc & 26,000 & 630,000 & 2,300 & 61,000 \\
\hline
\end{tabular}


Table 2. State residential and industrial risk-based concentrations of selected metals. All values are in milligrams per kilogram. - Continued

\begin{tabular}{lcccc}
\hline \multicolumn{1}{c}{ Metal } & EPA Residential $^{*}$ & EPA Industrial $^{*}$ & Texas Residential & Texas Industrial \\
\hline Arsenic & 0.61 & 2.4 & 24 & 200 \\
Cadmium & 70 & 800 & 52 & 850 \\
Copper & 3,100 & 41,000 & 550 & 39,000 \\
Lead & 400 & 800 & 500 & 1,600 \\
Nickel & 1,500 & 20,000 & 840 & 8,800 \\
Zinc & 23,000 & 310,000 & 9,900 & 250,000 \\
\hline
\end{tabular}

*If a State does not have its own standards, EPA risk-based concentrations at target cancer risk of $1.0 \mathrm{x} 106$, and with a target hazard quotient of 1.0 is used.

\section{Technical Problems with XRF Instrument}

Technical problems with the XRF instrument arose during this study. The instrument provided some suspicious results for some metals during fieldwork, even after field samples were reprocessed and remeasured with the XRF in the laboratory. Later, the instrument became more unreliable and was returned to the manufacturer for repair and recalibration. This recalibration failed to restore reliable performance for this particular XRF instrument for all metals. A subset of samples was sent to a commercial laboratory for analysis that used an inductively coupled plasma method. These results confirmed that all of the XRF readings for antimony, chromium, cobalt, and vanadium were unreliable. The study was not setup in a way that the source of the unreliability of the XRF results could be determined. However, XRF values for lead and arsenic, the main residual contamination at some of the sites, were generally within reasonable tolerances when compared against the results determined using the inductively coupled plasma method. Only the results for lead and arsenic are included here in further assessment of the potential use of remote sensing methods as tools for monitoring residual metal contamination.

\section{Hydrocarbons}

Hydrocarbons are organic compounds consisting entirely of hydrogen and carbon. They naturally occur, such as in crude oil. Different hydrocarbon molecules can bond, or catenate, with other hydrocarbon molecules and create a variety of additional hydrocarbon compounds. All hydrocarbons belong to a functional group that facilitates combustion and are thus hazardous because they are ignitable.

Remote sensing of hydrocarbons and their effects comprises a major body of work related to remote sensing of environmental contamination. Hydrocarbons can be detected by remote sensing methods in a number of ways, including basic aerial photo interpretation, microwave imagery, airborne video, multispectral satellite imagery, and hyperspectral imagery (HSI). Basic reflectance and morphological characteristics related to the presence of hydrocarbons on the surface of terrestrial or marine environments can be identified using remote sensing (Jha and others, 2008).

The basic spectral reflectance properties of hydrocarbons and the potential for remote sensing analysis was demonstrated by Cloutis (1989), who found that many organic compounds display electronic transitions that are the result of the excitation of bonding. The direct remote sensing detection of common hydrocarbons, such as oil and gasoline, is spectrally related to absorptions in the area of 1,200; 1,730; and 2,310 nm (King and Clark, 1989; Cloutis, 1989; Allen and Krekeler, 2010). Figure 4 shows the three distinctive absorptions of hydrocarbons in the solar-reflected spectrum. The spectra of all soil samples were examined for evidence of hydrocarbons. 


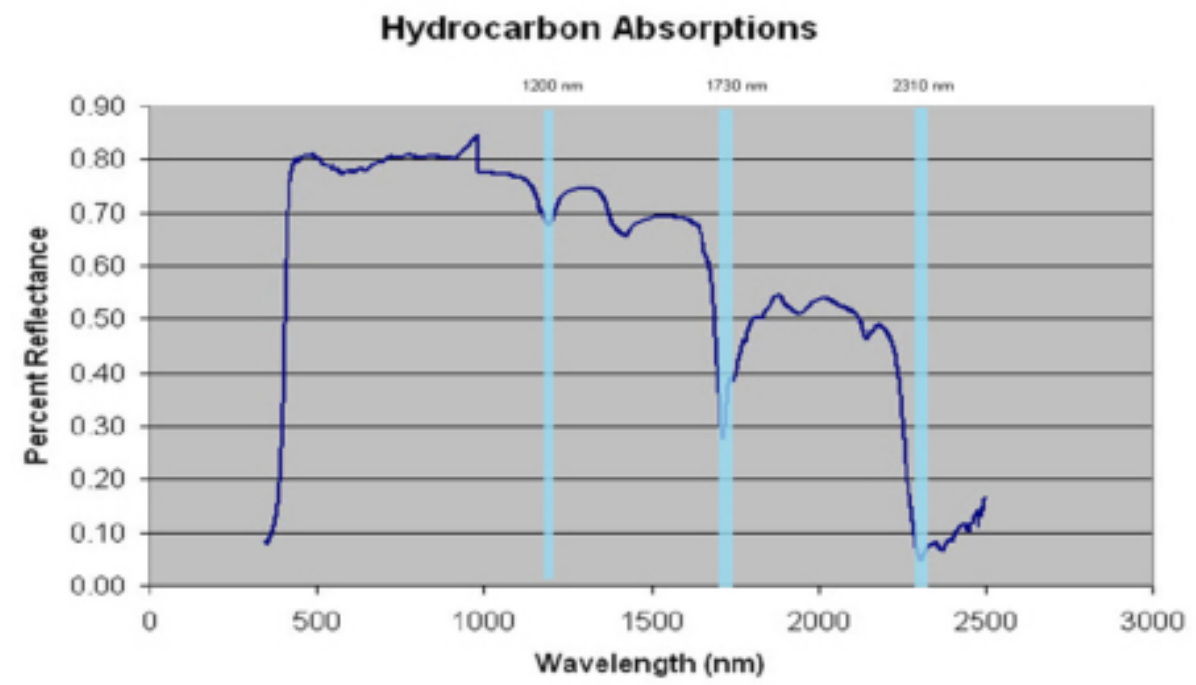

Figure 4. Spectra of typical hydrocarbon absorption features occurring at or near 1,200; 1,730; and 2,310 nm (King and Clark, 1989; Cloutis, 1989).

\section{Asbestos}

Asbestos contamination in soil is a concern at some Brownfields sites (see fig. 1). Asbestos comprises a set of silicate minerals that were commonly used as insulation in buildings throughout most of the 20th century. After discovery of the toxic effects of asbestos, its use declined considerably; however, asbestos insulation is still found in many older buildings and can contaminate the soils of Brownfields sites where older buildings have been torn down (Bassani and others, 2007).

Asbestos minerals, such as serpentine, tremolite, and chrysotile, have distinctive absorption features in the solar reflected spectrum and could be detected by solar-reflected spectroscopy and imaging spectroscopy, such as those used in this study. Absorption features at or near 1,385 nm and 2,320 nm are characteristic of asbestos and could be reflected in soils that are contaminated with residual asbestos fibers. Figure 5 shows a typical asbestos spectrum with the characteristic absorptions highlighted.

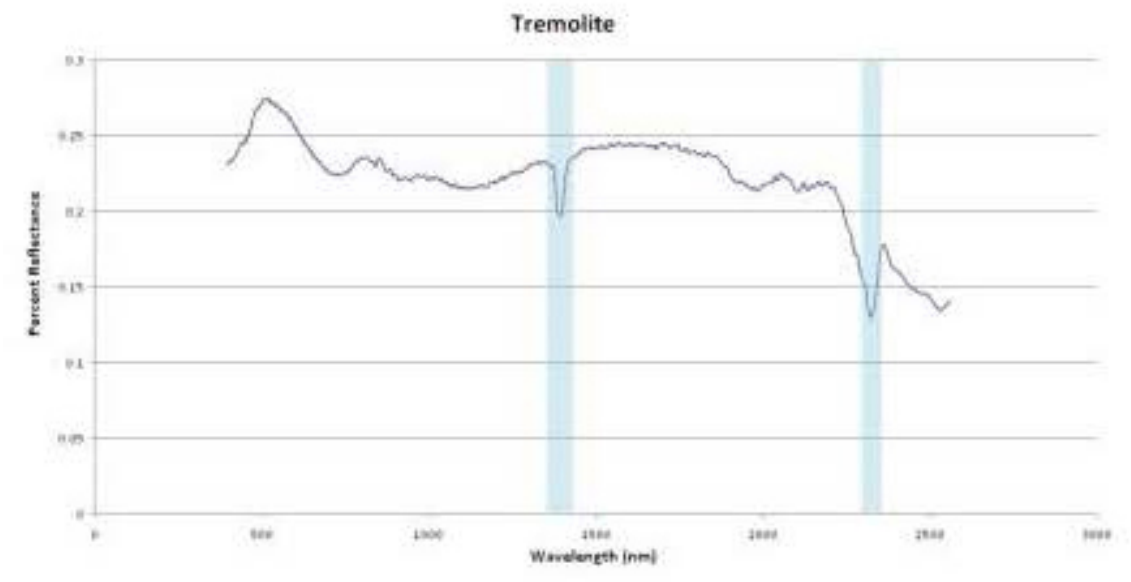

Figure 5. Asbestos minerals, such as tremolite, have distinctive absorption features at or near 1,385 and 2,320 nanometers $(\mathrm{nm})$. 
Residual asbestos in soils has not been documented in an imaging spectroscopic investigation. The successful detection would be a major discovery for potential hyperspectral applications. Swayze and others (2009) used airborne spectral data to successfully map asbestos minerals in California. Clark and others (2001) mapped fugitive serpentine in the World Trade Center dust after the September 11, 2001 attacks, but could not identify the asbestos form of the mineral. The spectra of all soils samples were examined for evidence of asbestos. Table 3 shows the contaminants and spectral areas of interest based on a review of the literature.

Table 3. Contaminants, stress, and spectral wavebands investigated in this study.

\begin{tabular}{llll}
\hline \multicolumn{1}{c}{ Contaminant } & \multicolumn{1}{c}{ Spectral Wavebands $(\mathbf{n m})$} & \multicolumn{1}{c}{ Reference } & \multicolumn{1}{c}{ Comment } \\
\hline Asbestos & 1383,2320 & Clark and others, 2001 & Contaminant of concern. \\
Metals & $500,1400,1900,2200,610 / 500$, & Kemper and Sommers, 2002 & Vegetation stress indices also. \\
& $1344 / 778,2200$ & Choe and others, 2008 & Gannouni and others, 2012 \\
& & King and Clark, 1989 & Cloutis, 1989 \\
Hydrocarbons & $1200,1731,2310$ & & \\
& & & \\
\hline
\end{tabular}

\section{Methodology}

\section{Remote Sensing Data Collection and Analysis}

Remote sensing data were collected in two forms. First, hyperspectral data were collected for each site during 2013 using the Civil Air Patrol's, Airborne Real-Time Cueing Hyperspectral Enhanced Reconnaissance (ARCHER) system. In addition, soil samples were processed in the laboratory with an Analytical Spectral Devices (ASD) full-range field spectroradiometer and analyzed for potential hydrocarbon, metal, and asbestos signatures that have been demonstrated in the near-infrared region. Figure 6 shows the two data collection strategies. The combination of imagery and the ASD laboratory analysis represents a full analysis of potential contaminant signatures that might exist in the solar-reflected portion of the electromagnetic spectrum from 400 to $2,500 \mathrm{~nm}$. Figure 7 shows the coverage of the two sensors in the electromagnetic spectrum.

ARCHER uses a grating spectrometer and includes 52 bands covering the $500 \mathrm{~nm}$-to-1,100 nm spectral range. The system uses a special camera facing down through a quartz glass portal in the belly of the aircraft. The aircraft is typically flown at 2,500 ft $(800 \mathrm{~m}$ ) altitude (above ground level) and 100 knots $(50 \mathrm{~m} / \mathrm{second})$ ground speed, thus facilitating the collection of image data with a 1-m spatial resolution and a 500-m image swath width. The ARCHER system has a 36-degree field of view and a 100:1 signalto-noise ratio. ARCHER combines a hyperspectral imaging system with a high-resolution, visible panchromatic imaging sensor and an integrated geopositioning and inertial navigation unit with onboard real-time processing for data acquisition, correction, and precision image georegistration (Civil Air Patrol, 2009). ARCHER technical details can be found in Stevenson and others (2005). 

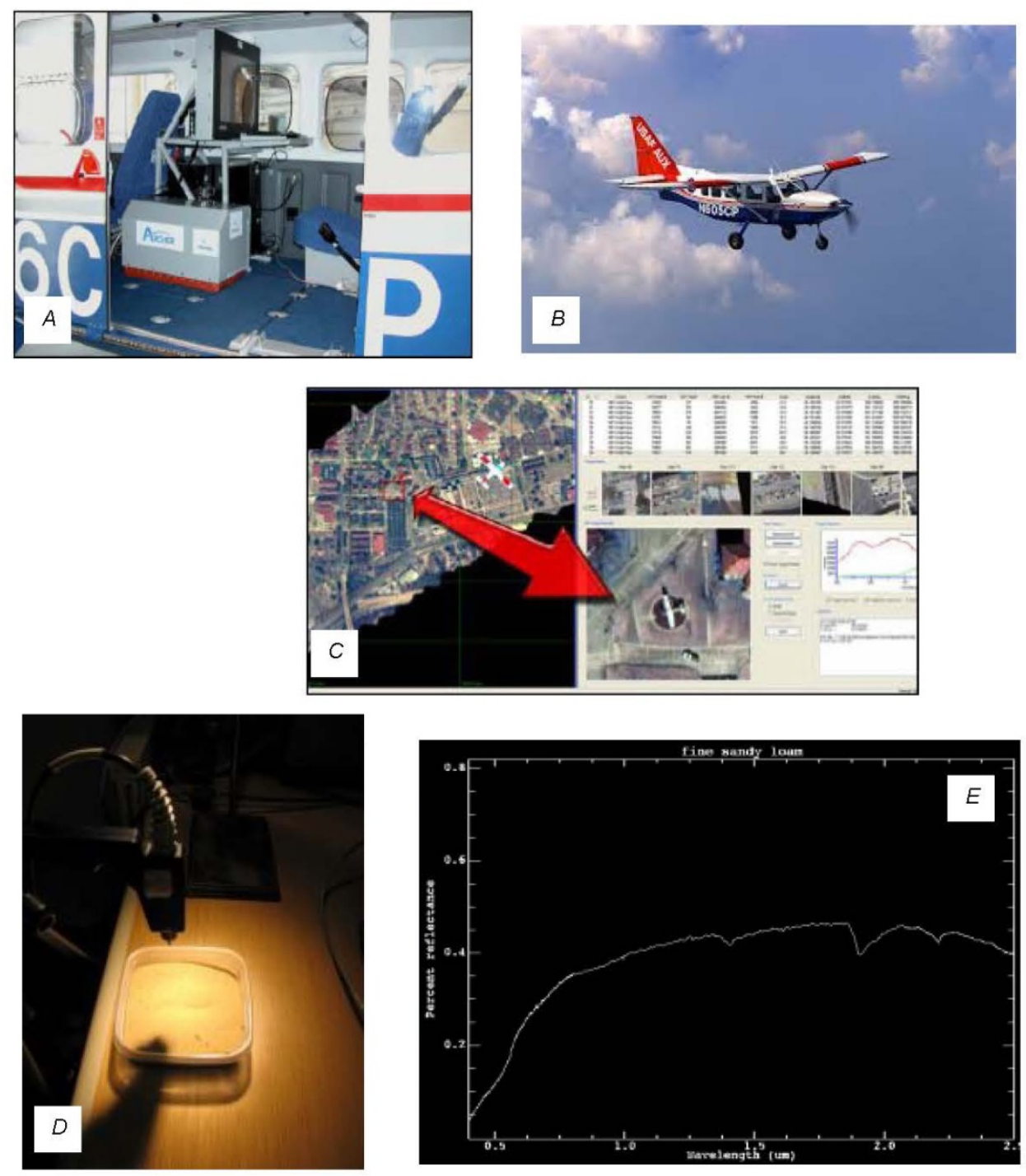

Figure 6. The combined hyperspectral techniques used in this report: $A$, the Civil Air Patrol's Airborne Real-Time Cueing Hyperspectral Enhanced Reconnaissance (ARCHER) sensor; $B$, the Civil Air Patrol aircraft; $C$, imagery and spectra from the ARCHER sensor; $D$, full-range spectroscopy in the laboratory with the Analytical Spectral Devices (ASD) spectroradiometers; and $E$, an example spectra of soil from the ASD point spectrometer. 


\section{SOLAR REFLECTED SPECTRUM}

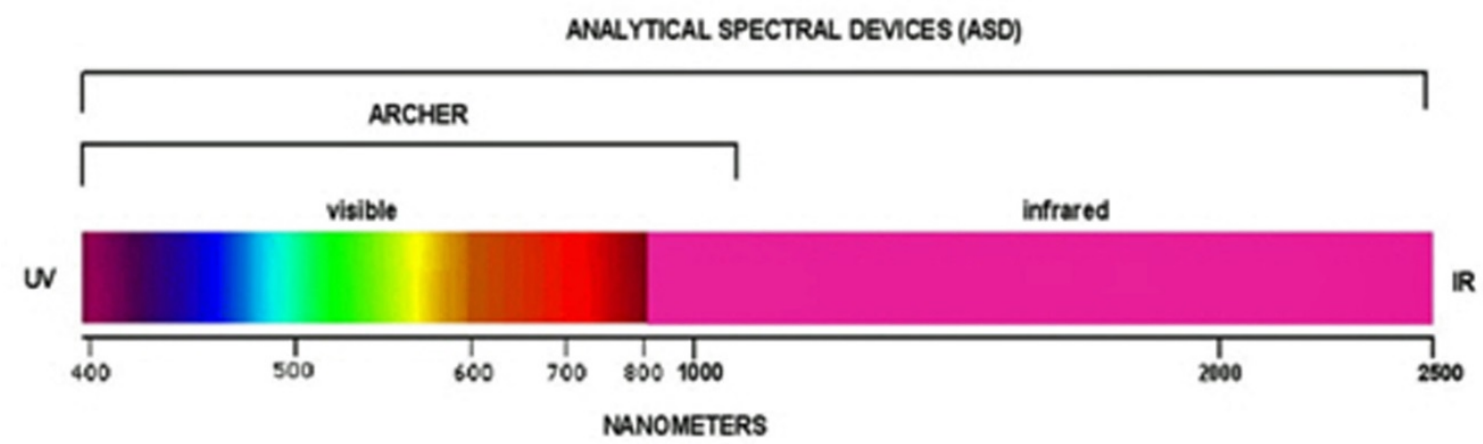

Figure 7. The solar-reflected electromagnetic spectrum coverage of the Civil Air Patrol's Airborne Real-Time Cueing Hyperspectral Enhanced Reconnaissance (ARCHER) system and Analytical Spectral Devices (ASD) instruments.

Soil samples were spectrally processed in the laboratory and examined for signs of metals, hydrocarbons, and asbestos. Spectral processing of resulting spectra were accomplished using Processing Routines in Interactive Data Language (IDL) for Spectroscopic Measurement (PRISM) (Kokaly, 2011) for spectral features that have been reported in the literature to be related to the reflectance of contaminants in soils.

\section{Image Processing}

The airborne imagery was converted from the native ARCHER format to an image-processing compatible format utilizing ARCHER processing software. The hyperspectral images were further processed by assigning specific wavelengths to each individual band. An atmospheric correction was applied to each image using an ENVI (ITTVIS, Boulder, Colorado) Quick Atmospheric Correction function (Bernstein and others, 2005; Exelis Visual Information Systems, 2014b). Image files were then converted into relative reflectance (percent reflectance), using a Band Math function within ENVI, to allow direct spectral comparisons with most spectral libraries. A basic agricultural stress index was calculated using standard formulas within the ENVI software (Exelis Visual Information Systems, 2014a). Images were then compared to the sampling results to identify anomalies and spatial correlations with possible hydrocarbon, asbestos, or metal residual contamination.

\section{Site Visit Data Collection and Analysis}

Field visits for site inspection and sample collection and analysis were conducted in 2013. Arrangements for site visits were coordinated through the EPA Regional Office and with the appropriate land owners and administrators. During visits, sites were reviewed for general conditions and visual appearance, and local personnel were interviewed when available. Sampling was conducted with an approximate grid pattern and at specific areas of interest based on visual observations. Soils were screened for metals using a portable XRF unit (fig. 8). Soil samples were collected for laboratory XRF and spectral analysis. 


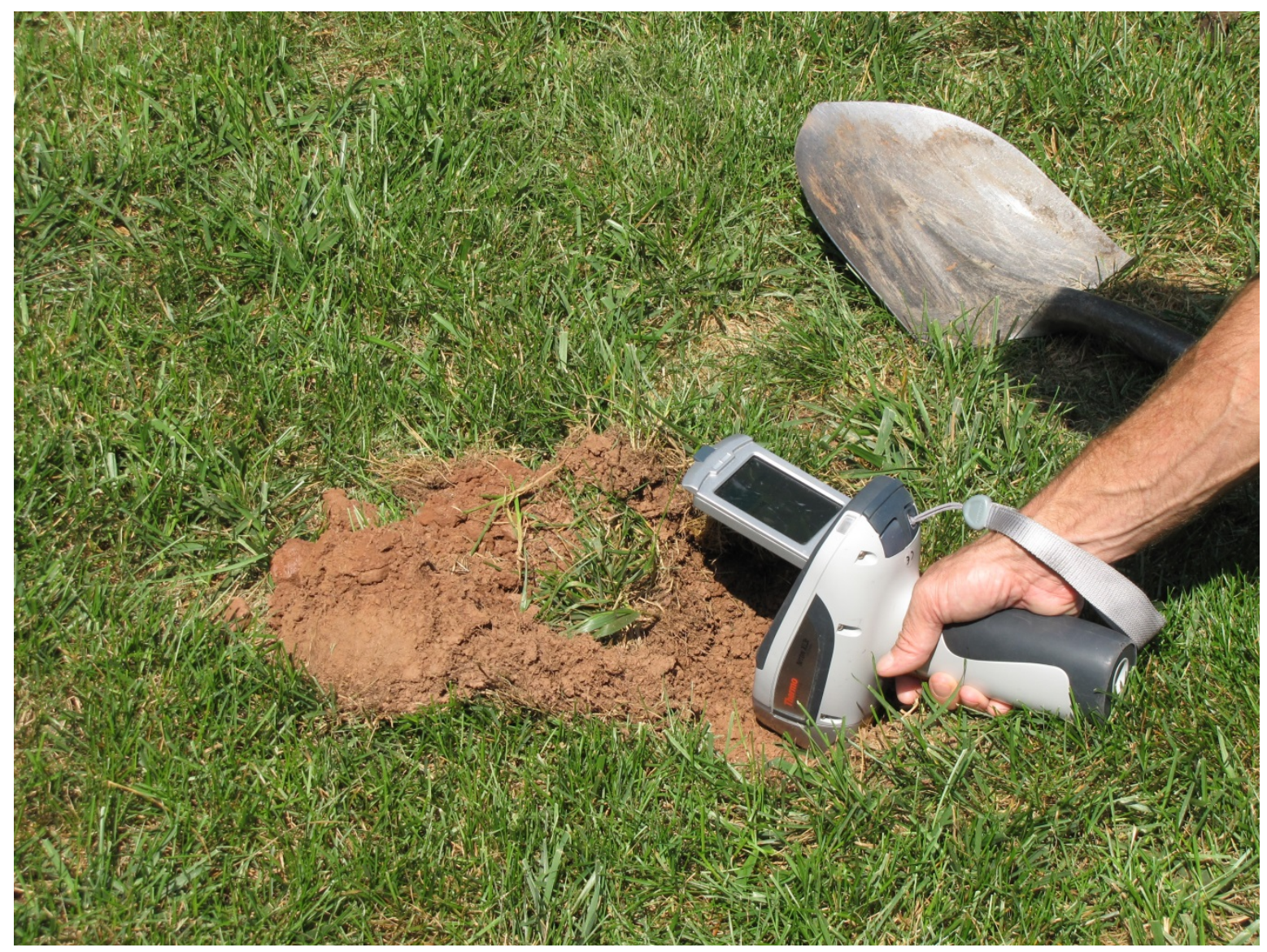

Figure 8. Soil sampling and field X-ray fluorescence screening.

\section{Laboratory Analysis and Quality Control}

Soil samples were analyzed for metals in the laboratory using XRF methods. After each soil sample was air dried, disaggregated, and sieved through a \#10 (2-millimeter) mesh, it was placed in a sample cup and analyzed for metals with a cradled XRF analyzer for a minimum of 3 minutes.

Soil samples were also analyzed in the laboratory with an ASD full-range spectroradiometer for the presence of hydrocarbons and asbestos fibers. This analysis facilitated detailed spectral analysis in the full solar-reflected spectrum, from 400-2,500 nm.

Some soil samples, where there were spectral or XRF indications of possible contamination, were analyzed by an independent laboratory. A complete description of the fieldwork, sampling, and quality control procedures can be found in Slonecker and Fisher (2009).

\section{Results}

\section{Soil Sampling}

Some soil samples exceeded applicable risk-based standards based on the laboratory XRF results. In Florida, four sites-210 North 12th Street, 22nd Street Mixed Use, Clearwater Auto, and Encore Retail Site - displayed multiple high values for arsenic and (or) lead. Two of these sites are not RAU, and the high concentrations are not surprising. However, two of the sites (22nd Street Mixed Use and Clearwater Auto) had been declared RAU. In Texas, one site - Cadiz Street — showed multiple high values for lead (fig. 9). 
In South Carolina, two adjacent sites_-Arkwright Mills and North Street Dump — had multiple samples that exceeded the industrial standard for arsenic. In Louisiana, one site-Syngenta Crop Protection-had one sample that exceed the industrial standard for arsenic. There were no spectral indications of hydrocarbons at any of the sites.

Although the spectra of all samples were examined in the laboratory for signs of asbestos and were found to be negative, 11 samples were sent for formal analysis of asbestos fibers. Samples were analyzed using Transmission Electron Microscopy (TEM). Samples were dissolved in tetrahydrofuran or ashed in a furnace. The insolubles or ash were separated and dried. The dry insolubles/ash were transferred to a TEM grid and examined. Quantitative samples were weighed and aliquot slurried and filtered. Fiber volume from TEM examination was converted to weight and the percent calculated. In some cases, volume area estimates were made and converted to weight percent. All samples were negative for asbestos (MACS Lab, 2013b).

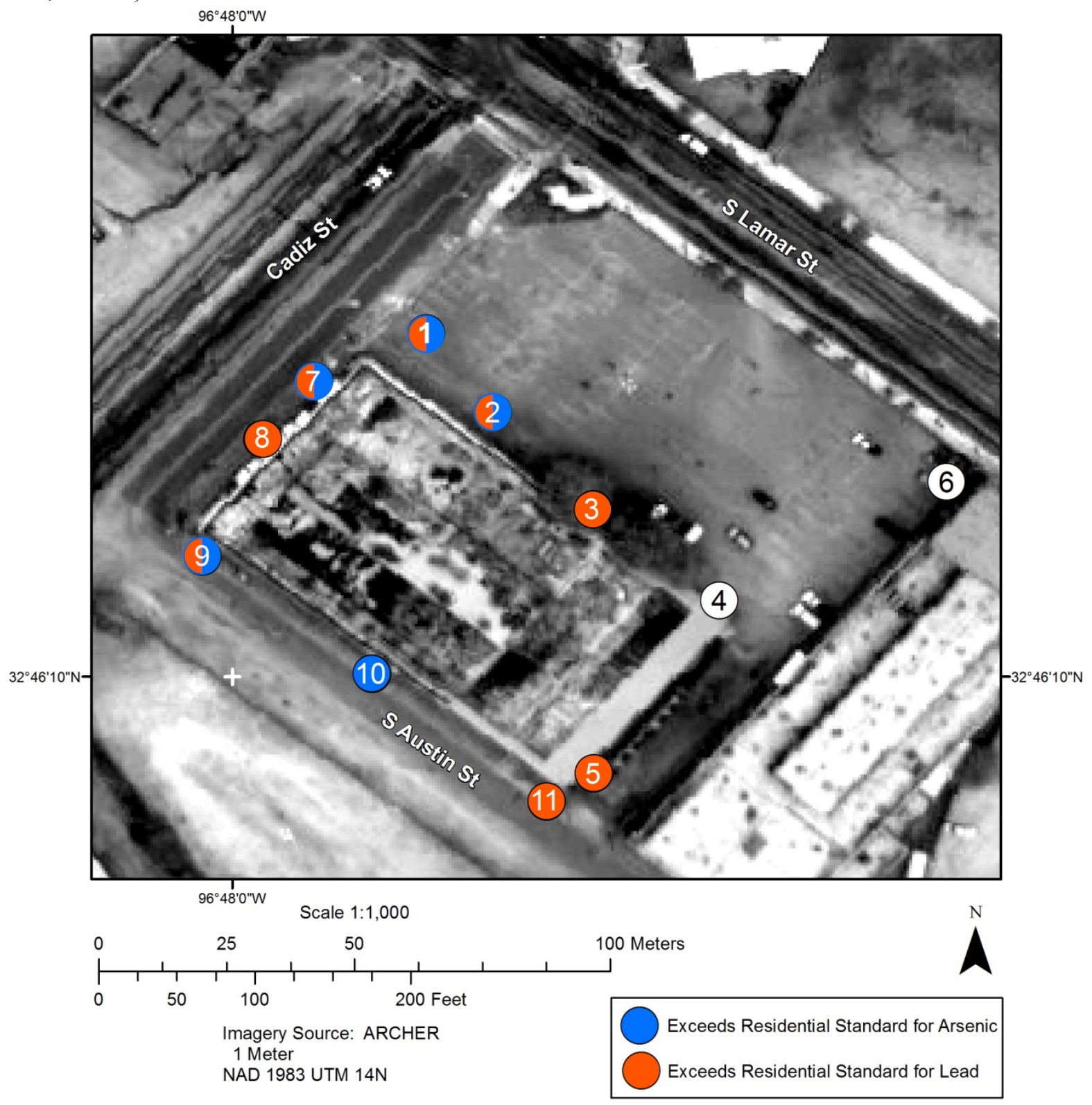

Figure 9. Sampling locations at the Cadiz Street Site in, Dallas, Texas. Three samples (1, 3, and 11) showed lead levels exceeding industrial standards. ARCHER panchromatic image, September 30, 2013. 


\section{Hyperspectral Imagery Results}

A series of hyperspectral vegetation indices were computed and evaluated in relation to the spatial pattern of the field sampling. Clear patterns of vegetation stress, likely related to elevated metals in the soil, were observed at three of the five sites showing high concentrations of arsenic and (or) lead in the soil. On these images of composite stress index, black only represents extreme stress when the pixel is vegetation. Concrete, road, roof, and other constructed surfaces also return a black color but do not represent vegetation stress. Vegetation stress images must be viewed in the context of cover vegetation to be effective. However, this can be difficult when there is patchy vegetation, areas of bare soil, and manmade surfaces.

Figures 10-12 show three sites where metal contamination was observed in the soil samples and the analysis of the hyperspectral imaging indicated vegetation stress. One of these sites had been cleaned up and declared RAU. The other two sites are the Brownfield sites where contaminants have not been addressed.

Figure 10 depicts the important soil sampling and hyperspectral image processing results for 210 North 12th Street, Tampa, Florida. On the left is a panchromatic ARCHER image with field sampling locations. Soil samples with arsenic concentrations above the Florida State RBCS are shown in blue. On the right, a standard agricultural stress composite index image shows high levels of vegetation stress in red and black.

Figure 11 shows soil sampling and hyperspectral image processing results for the Encore Retail Site, in Tampa, Florida. On the left is a panchromatic ARCHER image with field sampling point locations. On the right, the hyperspectral image showing the agricultural stress composite index indicates high levels of vegetation stress in red and black. High lead readings were recorded at sample points 1, 2, 3, and 9. Elevated lead readings (substantially above background, but not exceeding residential standards) were also observed at points 7,8 10, and 11. A large area of vegetation stress is shown in the northeast part of the site where the vegetation appears normal on the panchromatic image but highly stressed on the hyperspectral image (fig. 11).

Figure 12 shows the soil sampling and hyperspectral image processing results for the Clearwater Auto, Clearwater, Florida. On the left, a panchromatic ARCHER image shows the field sampling point locations. On the right is an ARCHER hyperspectral image of the agricultural stress composite index that shows high levels of vegetation stress in red and black. Elevated lead values were observed at points 4, 5 , $6,7,8$, and 9. Stress index results suggest the residual contamination may be more extensive than indicated by soil sampling results alone.

Figure 13 shows the limitations of the hyperspectral imaging to detect residual metal contamination in soils at forested sites. Based on preliminary soil analysis results, EPA extensively resampled these sites and found other isolated locations with elevated metals (Tetra Tech, 2013). Even using different parameters in the image processing to take into account the forested nature of the site, the hyperspectral imaging did not reveal vegetation stress in the vicinity of the elevated metals. The EPA determined that the residual contamination at this site is not high enough or extensive enough to warrant further investigation (Henry, 2014).

The site shown in figure 9 indicates another limitation of the hyperspectral imaging. At this site, the high lead concentrations were found in the soil near the building. Any stress that may have been in the vegetation could not be detected remotely. (Vegetation stress image is not included in fig. 9.) 
A

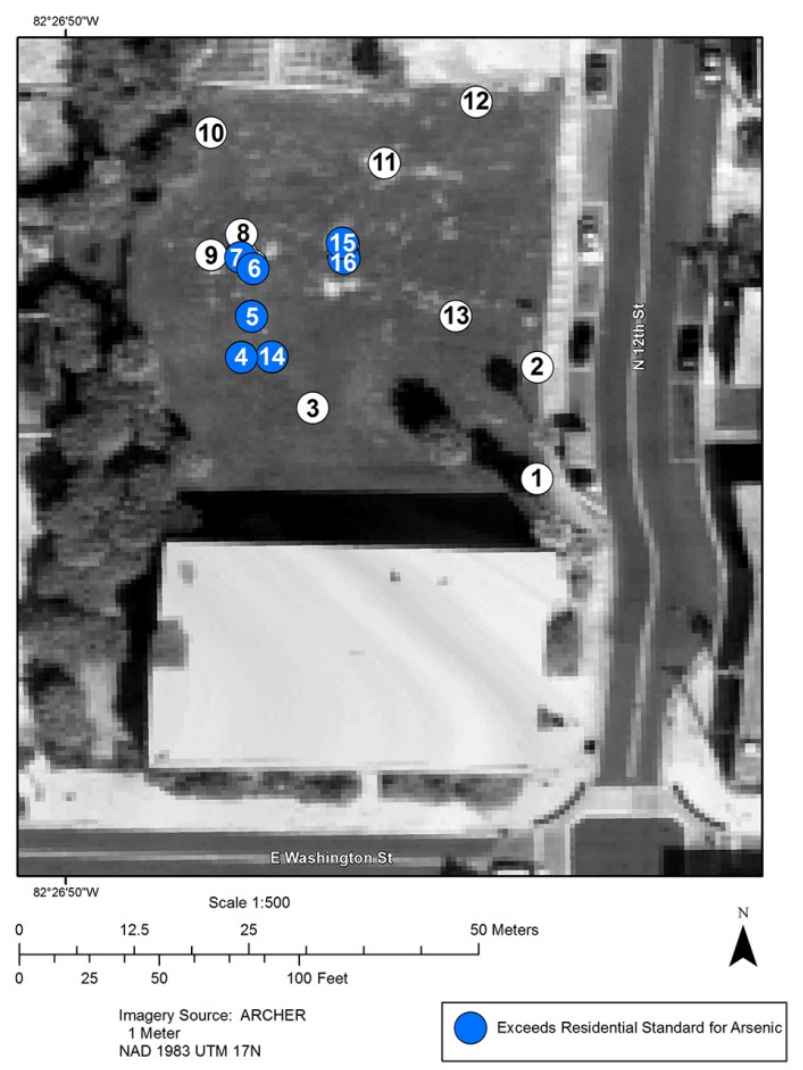

\section{$B$}

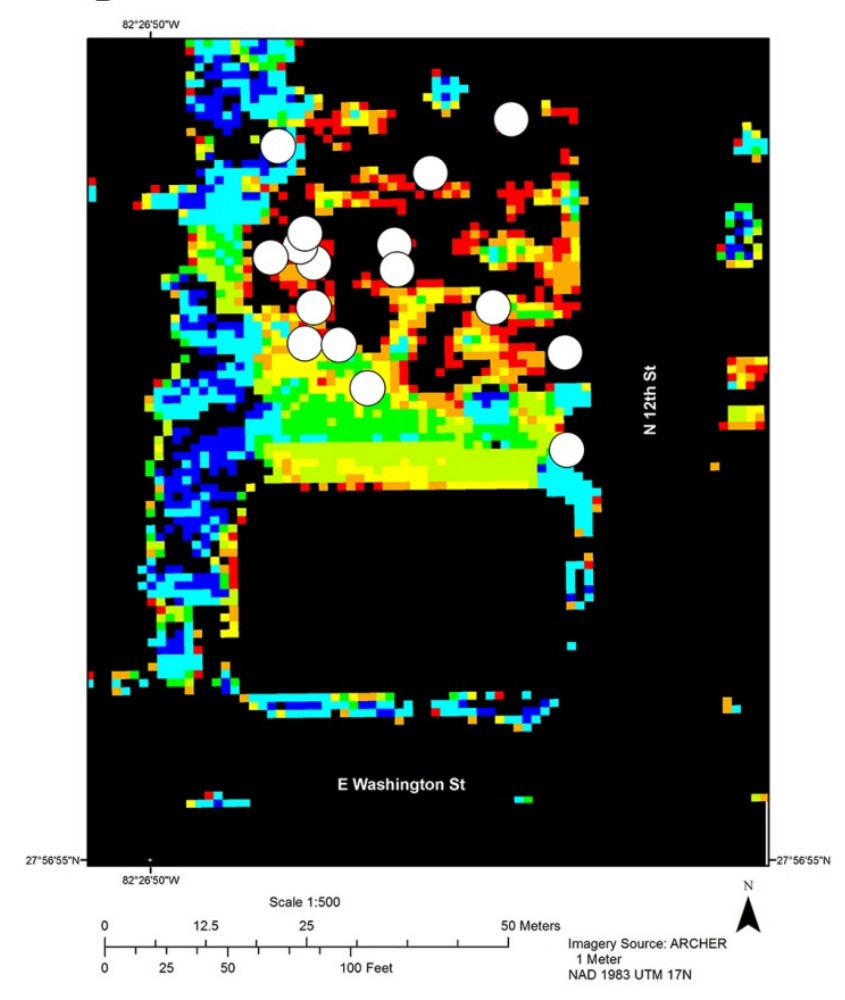

Figure 10. ARCHER Hyperspectral Image Processing Results for 210 North 12th Street, Tampa, Florida. $A$, Panchromatic ARCHER image with field sampling locations. The high arsenic readings are shown in blue. $B$, The agricultural stress composite index image shows high levels of vegetation stress in red and black. Both images dated March 20, 2013. 

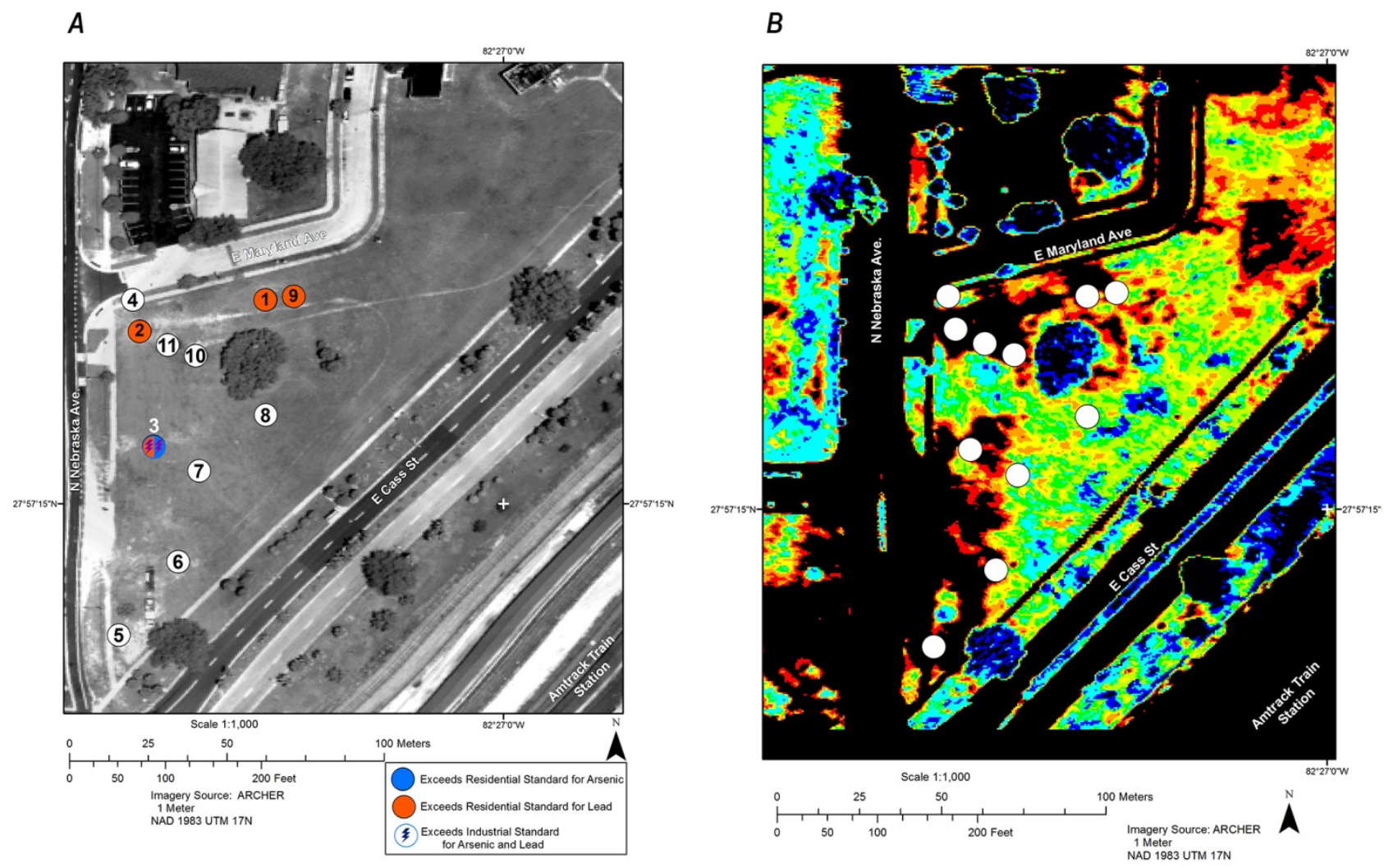

Figure 11. ARCHER Hyperspectral Image Processing Results for the Encore Retail Site, in Tampa, Florida. $A$, Panchromatic ARCHER image with field sampling locations. $B$, The agricultural stress composite index shows high levels of vegetation stress in red and black. High lead readings were recorded at sample points. Lead above residential standards was observed at points 1,2,3, and 9 . Elevated lead readings (substantially above background, but not exceeding residential standards) were also observed at points 7, 810 , and 11 . Additional vegetation stress is shown in the northeast area of the site where samples were not taken. Both images dated March 30, 2013. 
A

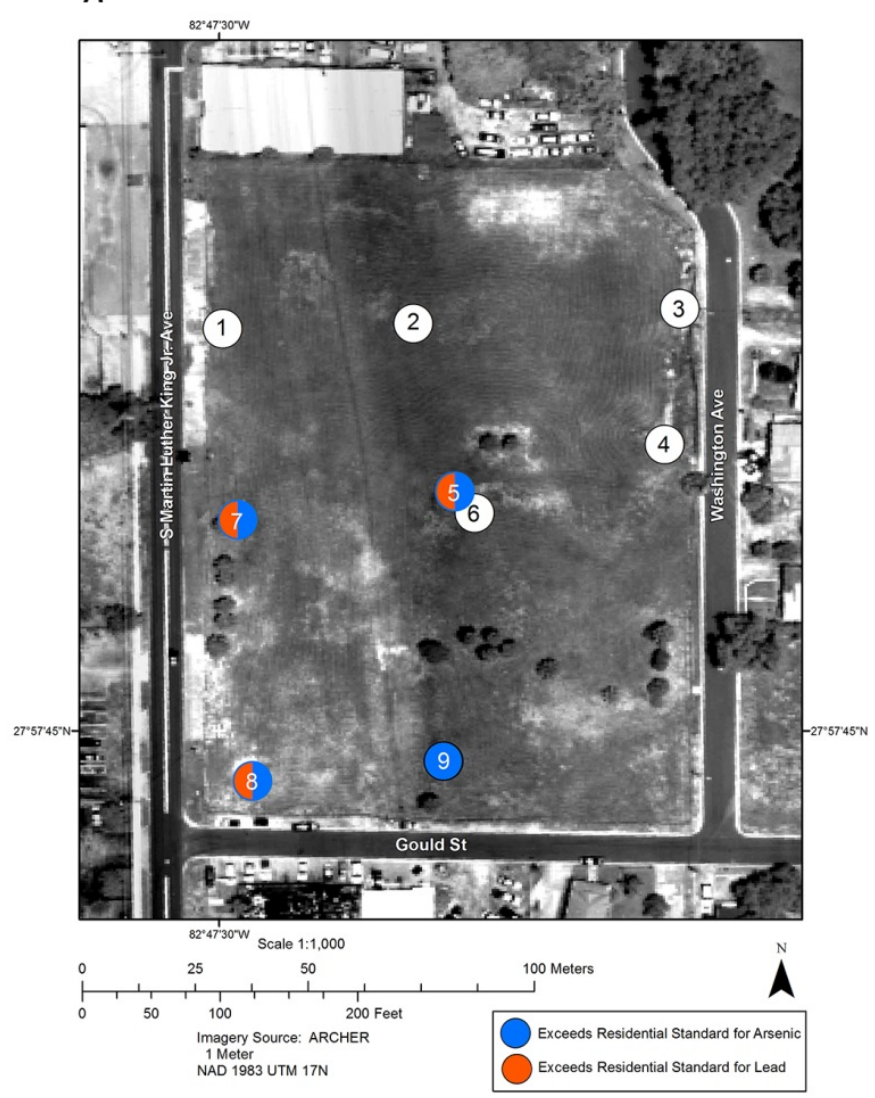

B

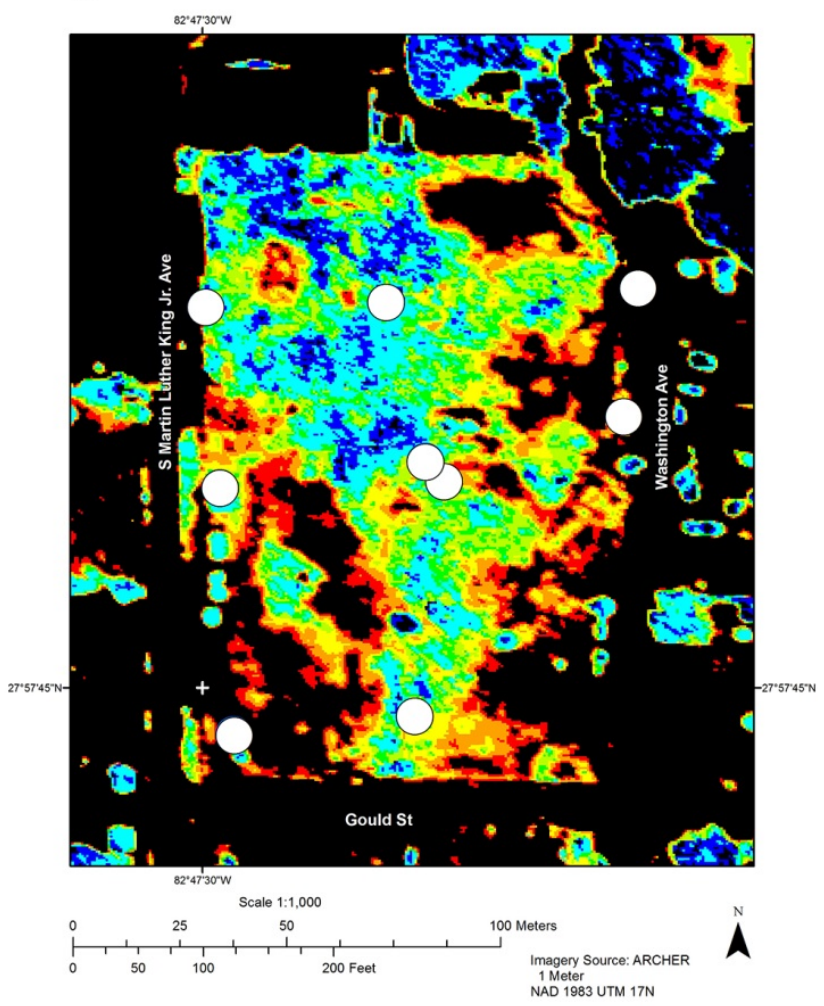

Figure 12. ARCHER Hyperspectral Image Processing Results for the Clearwater Auto Site, Clearwater, Florida. $A$, Panchromatic ARCHER image with field sampling locations. $B$, The agricultural stress composite index shows high levels of vegetation stress in red and black. Elevated lead and arsenic values were observed at points 5,7 , and 8 . Stress index results suggest the residual contamination may be more extensive than indicated by sampling results. 
$A$

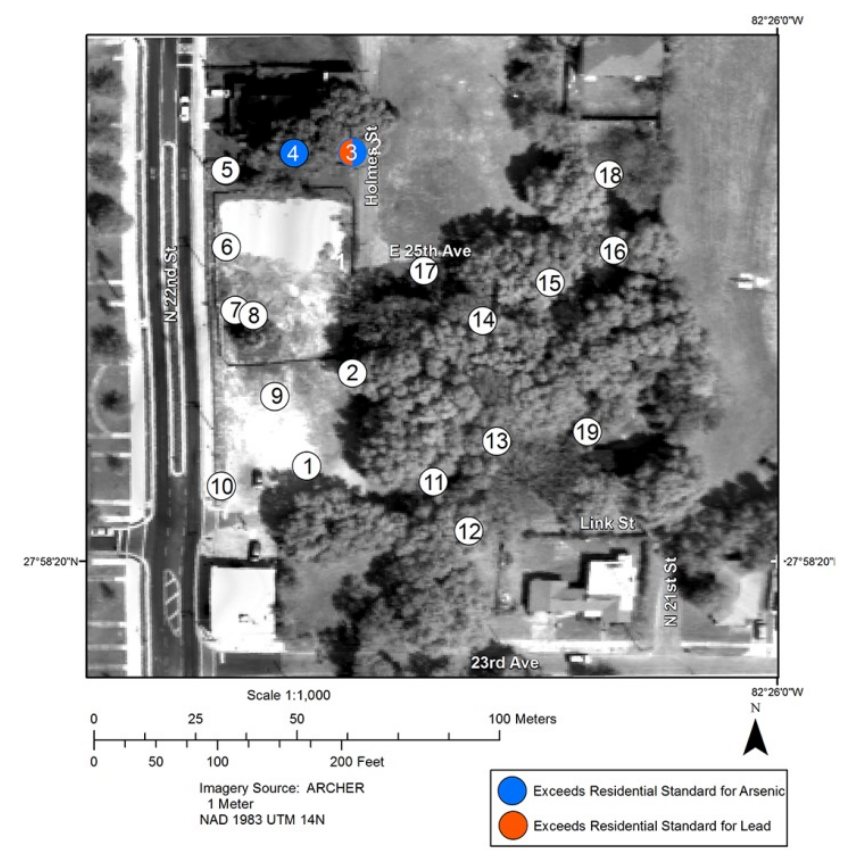

B

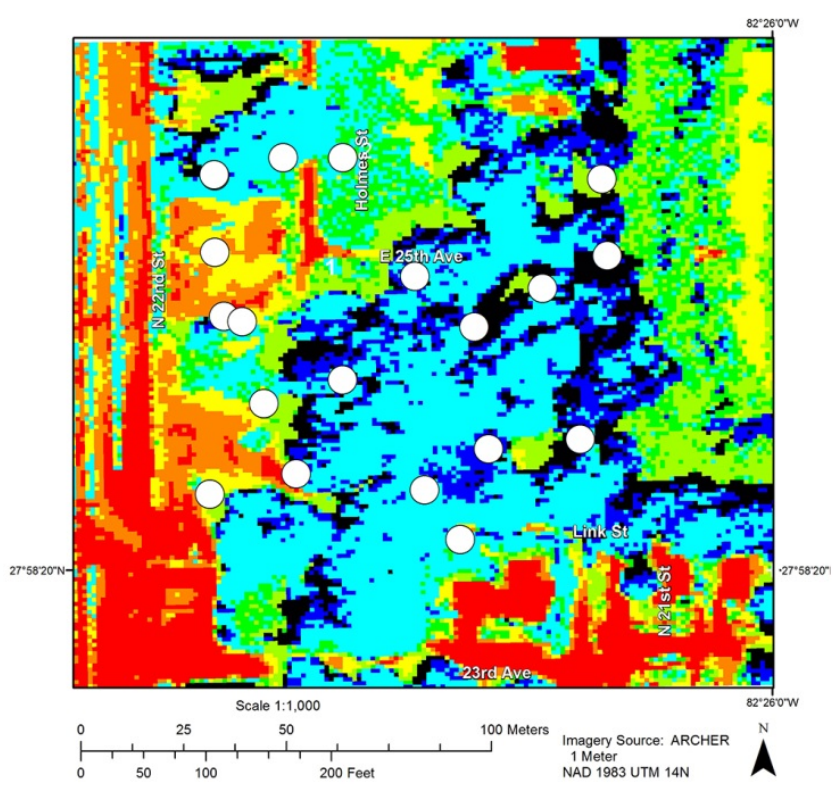

Figure 13. ARCHER Hyperspectral Image Processing Results for the 22nd Street Mixed-Use Site. A, Panchromatic ARCHER image with field sampling locations. Two minor exceedances for lead (Samples 3 and 4). B, A vegetation stress composite index shows no stress indications in the vegetation. Red areas are constructed surfaces and black areas are the result of tree shadows. This image was processed using different parameters than those used to create the agricultural stress images in figures 10-12 to take into consideration the forested nature of this site.

\section{Soil Spectral Processing}

ASD spectra of each soil sample were processed in the laboratory in order to identify the presence of hydrocarbons, asbestos, and specific spectral features based on signatures of those materials documented in previous literature and to evaluate against the metal concentrations found. No evidence of hydrocarbons and (or) asbestos was detected. Only the area of the absorption feature at 2,200 nm shows a potentially important relationship with lead in the soil at the sites evaluated. Using PRISM, we computed the areas of the 2,200-nm feature for each sample (fig. 14A) and plotted these areas against the concentrations of metals measured in the samples at the three sites where we identified vegetation stress (figs. 10-12). We found the areas displayed a power law relationship when plotted against the lead concentrations in samples from two sites (Clearwater Auto, fig. 14 right and Encore Retail Site, not shown). Power law relationships show one parameter changing relative to the other. In this case, the feature area is inversely correlated with the lead concentration. However, this relationship is not proof that the lead in the samples causes the spectral response. It is likely that the lead concentration in these samples is related to some other characteristic of the soil, such as organic content, which may cause the absorption response. This power law relationship was not found at the third site. More research is required to fully understand this effect, but a potential result of a remote spectral indicator of lead concentration in soils is suggested by the relationship. 


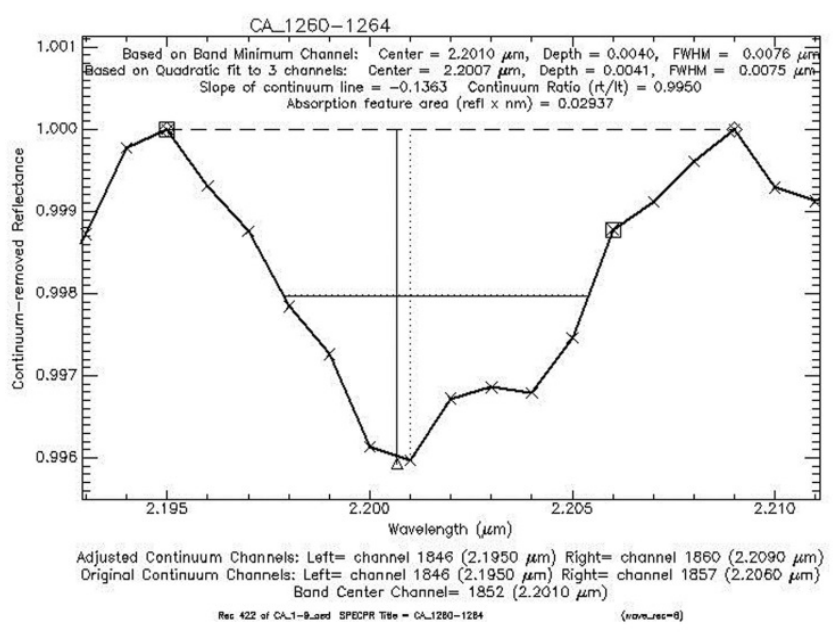

$B$

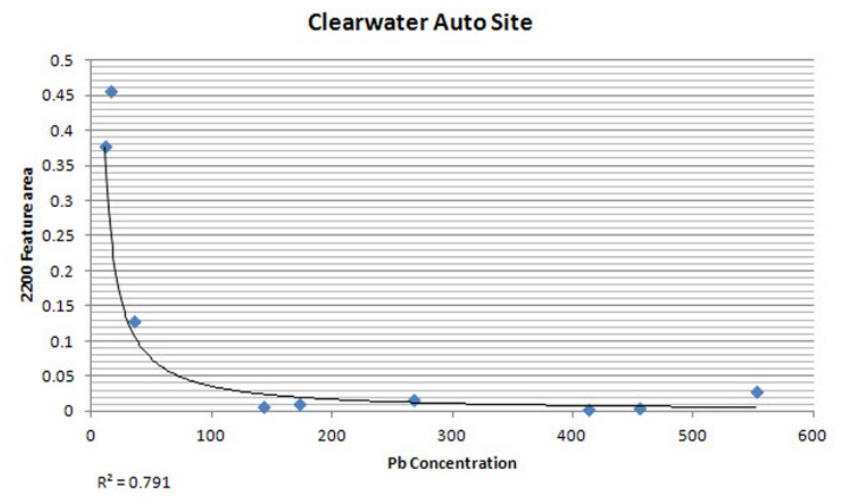

Figure 14. Spectral Absorption Feature area at 2,200 nm. A, Computation of the 2,200-nm absorption feature area using the Processing Routines in the Instrument Development Laboratory for Spectroscopic Measurement and $B$, the power law relationship between the lead concentration and this feature from the soil samples at the Clearwater Auto Site (right).

\section{Summary and Conclusions}

This report is the fourth in a series that examined hyperspectral technology as a potential tool for site monitoring. (See USGS Open-File Reports 2009-1048, 2011-1050, and 2014-1081.) Hyperspectral technology has the potential to be a useful tool for monitoring sites that have been declared RAU under a land cleanup program. Energy interacts with matter, such as metals, and presents a unique spectral "signature." Residual contamination could potentially be identified remotely based on this signature, eliminating or reducing the need for site visits and in-situ sampling.

In general, at most of the RAU sites in these studies, there was little or no residual contamination to detect. Although assessing the ability to monitor and detect potential problems at RAU sites were the objectives of the study, the relatively clean condition of most of the sites did not result in a thorough evaluation of remote sensing technologies under a variety of site conditions.

There were also several unexpected problems that affected the implementation of this study. There were hyperspectral acquisition issues with the Civil Air Patrol, which has been phasing out the ARCHER hyperspectral imager. Acquiring sufficient metadata and securing site access were also issues at several sites. Unreliable readings from the XRF instrument caused many delays and redundant and timeconsuming analyses to be performed.

There were some successes. At the three sites examined that had contamination, the hyperspectral imaging identified vegetation stress, potentially caused by heavy metal concentrations. At two of these sites, a relationship between the absorption feature area at 2,200 $\mathrm{nm}$ and lead concentrations was found.

Future research might benefit from a more deterministic approach where sites known to be contaminated are imaged to capture the hyperspectral signature of specific contaminants. If successful, a library of such signatures could prove to be a monitoring asset. Also, a series of laboratory experiments involving vegetation stress and specific contaminants might be considered for future research and could provide some critical insight into site-specific spectral signatures. 


\section{References Cited}

Allen, C.S., and Krekeler, M.P.S., 2010, Reflectance spectra of crude oils and refined petroleum products on a variety of common substrates, in Gilbreath, C.G., and Hawley, G.T., eds., Active and passive signatures: Proceedings of the International Society for Optics and Photonics, v. 7687, [unpaginated].

Baker, S.J., 1983, Historical aerial photographic analysis, Ringwood mines and landfills: U.S. Environmental Protection Agency Report TS-PIC-83044, 2 volumes.

Baldridge, A. M., Hook, S. J., Grove, C. I., and Rivera, G., 2009, The ASTER spectral library version 2.0: Remote Sensing of Environment, v. 113, no. 4, p. 711-715.

Bassani, C., Cavalli, R. M., Cavalcante, F., Cuomo, V., Palombo, A., Pascucci, S., and Pignatti, S. 2007, Deterioration status of asbestos-cement roofing sheets assessed by analyzing hyperspectral data: Remote Sensing of Environment, v. 109, no. 3, p. 361-378.

Bernstein, L.S., Adler-Golden, S.M., Sundberg, R.L., Levine, R.Y., Perkins, T.C., Berk, A., and Hoke, M.L., 2005, A new method for atmospheric correction and aerosol optical property retrieval for VISSWIR multi-and hyperspectral imaging sensors: QUAC (QUick Atmospheric Correction), Burlington, Mass., Spectral Sciences Inc.

Butler, L.R.P., and Laqua, K., 1995, Nomenclature, symbols, units and their usage in spectrochemical analysis, in Part IX; Instrumentation for the spectral dispersion and isolation of optical radiation: International Union of Pure and Applied Chemistry Recommendations 1995, 18 p.

Chang, S.H., and Collins, William, 1983, Confirmation of the airborne biogeophysical mineral exploration technique using laboratory methods: Economic Geology, v. 78, no. 4, p. 723-736.

Choe, E., van der Meer, F., Ruitbeek, F., van der Werff, H., Smeth, B. and Kim, K-W, 2008, Mapping of heavy metal pollution in stream sediments using combined geochemistry, field spectroscopy, and hyperspectral remote sensing - A case study of the Rodalquilar mining area, SE Spain: Remote Sensing of Environment, v. 11, no. 7, p. 3222-3233.

Civil Air Patrol (CAP), 2009, ARCHER - CAP advanced technologies: Civil Air Patrol presentation, 21 p., accessed April 14, 2011, at http://www.capmembers.com/medi a/cms/ARCHER_For Commanders_Jun_09_CE3C28CEC0754.pdf.

Clark, R.N., 1999, Spectroscopy of rocks and minerals, and principles of spectroscopy, chap. 1 of Manual of remote sensing, v. 3 of Rencz, A.N., ed., Remote Sensing for the Earth Sciences: New York, John Wiley and Sons, p. 3-58.

Clark, R.N., Green, R.O., Swayze, G.A., Meeker, G., Sutley, S., Hoefen, T.M., Livo, K.E., Plumlee, G., Pavri, B., Sarture, C., Wilson, S., Hageman, P., Lamothe, P., Vance, J.S., Boardman, J., Brownfield, I. Gent, C., Morath, L.C., Taggart, J., Theodorakos, P.M., and Adams, M., 2001, Environmental studies of the World Trade Center area after the September 11, 2001 attack: U.S. Geological Survey Open-File Report 2001-0429, accessed March 5, 2014, at http://speclab.cr.usgs.gov/wtc/.

Clark, R.N., Curchin, J.M, Hoeffen, T.M., and Swayze, G.A., 2009, Reflectance spectroscopy of organic compounds - 1. Alkanes: Journal of Geophysical Research, v. 114, no. E03001, p. 19.

Cloutis, E.A., 1989, Spectral reflectance properties of hydrocarbons; Remote-sensing implications: Science, v. 245, no. 4914, p. 165-168.

Exelis Visual Information Systems [2014a], Agricultural Stress Tool: Exelis Visual Information Solutions Web page, accessed March 12, 2014, at http://www.exelisvis.com/docs/AgriculturalStressTool.html. 
Exelis Visual Information Systems [2014b], Quick Atmospheric Correction (QUAC): Exelis Visual Information Solutions Web page, accessed June 16, 2014, at http://www.exelisvis.com/docs/QUAC.html.

Farrand, W.H., and Harsanyi, J.C., 1997, Mapping the distribution of mine tailings in the Coeur d'Alene River Valley, Idaho, through the use of a constrained energy minimization technique: Remote Sensing of Environment, v. 59, no. 1, p. 64-76.

Ferrier, G., 1999, Application of imaging spectrometer data in identifying environmental pollution caused by mining at Rodaquilar, Spain: Remote Sensing of Environment, v. 68, no. 2, p. 125-137.

Florida Department of Environmental Protection, 2005, Division of Waste Management, Chapter 62-777, Table II - Soil Cleanup Target Levels, accessed May 19, 2014, at http://www.dep.state.fl.us/waste/quick_topics/rules/.

Gamon, J.A., Peñuelas, J., and Field, C.B., 1992, A narrow-waveband spectral index that tracks diurnal changes in photosynthetic efficiency: Remote Sensing of Environment, v. 41, p. 35-44.

Gamon, J.A., Serrano, L., and Surfus, J.S., 1997, The photochemical reflectance index; An optical indicator of photosynthetic radiation use efficiency across species, functional types and nutrient levels: Oecologia, v. 112, p. 492-501.

Gannouni, S., Rebai, N. and Abdeljaoued, S., 2012, A spectroscopic approach to assess heavy metals contents of the mine waste of Jalta and Bougrine in the North of Tunisia: Journal of Geographic Information System, v. 4, p. 242-253.

Goetz, A.F.H., Vane, Gregg, Solomon, J.E., and Rock, B.N., 1985, Imaging spectroscopy for earth remote sensing: Science, v. 228, no. 4704, p. 1147-1153.

Green, R.O., Eastwood, M.L., Sarture, C.M., Chrien, T.G., Aronsson, M., Chippendale, B.J., Faust, J.A., Pavri, B.E., Chovit, C.J., Solis, M., Olah, M.R., and Williams, O., 1998, Imaging spectroscopy and the airborne visible/infrared imaging spectrometer (AVIRIS): Remote Sensing of Environment, v. 65, no. 3, p. $227-248$.

Henry, N., 2014, Administration Workpaper: Assignment: 2013 - 3790 - OPE-FY13-0019 - Cross Program Revitalization Measures - Hyperspectral Imaging in Region 4.

Horler, D.N.H., Barber, J., and Barringer, A.R., 1980, Effects of heavy metals on the absorbance and reflectance spectra of plants: International Journal of Remote Sensing, v. 1, p. 121-136.

Jha, M.N., Levy, J., and Gao, Y., 2008, Advances in remote sensing for oil spill disaster management: State-of-the-art sensors technology for oil spill surveillance: Sensors, v. 8, p. 236-255.

Kemper, T., and Sommer, S., 2002, Estimate of heavy metal contamination in soils after a mining accident using reflectance spectroscopy: Environmental Science \& Technology, v. 36, no. 12, p. 2742-2747.

King, T.V.V., and Clark, R.N., 1989, Reflectance spectroscopy (0.2 to $20 \mu \mathrm{m})$ as an analytical method for the detection of organics, in Proceedings of the First International Symposium; Field Screening Methods for Hazardous Waste Site Investigations: U.S. Environmental Protection Agency, p. 485-488.

Kokaly, R.F., 2011, PRISM: Processing routines in IDL for spectroscopic measurements (installation manual and user's guide, version 1.0): U.S. Geological Survey Open-File Report 2011-1155, 432 p., at http://pubs.usgs.gov/of/2011/1155/. 
Louisiana Department of Environmental Quality, 2003, LDEQ Screening Standards for Soil and Groundwater, LDEQ Recap Table 1, accessed May 19, 2014, at http://www.deq.louisiana.gov/portal/Portals/0/technology/recap/2003/RECAP\%202003\%20Text\%20Ta ble\%201.pdf.

MACS Lab Incorporated, 2013a, CAM-17 Bulk Material, EPA 3050/EPA 6010 Analysis Report 235896: MACS Lab Incorporated, December 13, 2013, 431 Crown Point Circle Site 120, Grass Valley, Calif., $12 \mathrm{p}$.

MACS Lab Incorporated, 2013b, Bulk Asbestos Analysis, Bulk TEM Report 235868: MACS Lab Incorporated, December 23, 2013, 431 Crown Point Circle Site 120, Grass Valley, Calif., 2 p.

Milton, N.M., Ager, C.M., and Eiswert, B.A., and Power, M.S., 1989, Arsenic- and selenium-induced changes in spectral reflectance and morphology of soybean plants: Remote Sensing of Environment, $\mathrm{v}$. 30, no. 3, p. 263-269.

Montero S.I.C., Brimhall, G.H., Alpers, C.N., and Swayze, G.A., 2005, Characterization of waste rock associated with acid drainage at the Penn Mine, California, by ground-based visible to short-wave infrared reflectance spectroscopy assisted by digital mapping: Chemical Geology, v. 215, no. 1, p. $453-472$.

National Aeronautics and Space Administration, 2007, AVIRIS concept, http://aviris.jpl.nasa.gov/html/aviris.concept.html.

National Aeronautics and Space Administration, 2010, AVIRIS Moffett Field Image Cube http://aviris.jpl.nasa.gov/html/aviris.cube.html.

Pandit, C.M., Filippelli, G.M., and Li, L., 2010, Estimation of heavy-metal contamination in soil using reflectance spectroscopy and partial least-squares regression: International Journal of Remote Sensing, v. 31, no. 15, p. 4111-4123.

Shacklette, H.T., and Boerngen, J.G., 1984, Element concentrations in soils and other surficial materials of the conterminous United States: U.S. Geological Survey Professional Paper 1270, 105 p., http://pubs.usgs.gov/pp/1270/pdf/PP1270_508.pdf.

Shepherd, K.D., and Walsh, M.G., 2002, Development of reflectance spectral libraries for characterization of soil properties: Soil Science Society of America Journal, v. 66, no. 3, p. 988-998.

Sheppard, S.C., 1991, Summary of phytoxic levels of soil arsenic: Water, Air and Soil Pollution, v. 64, p. $539-550$.

Slonecker, E.T., and Fisher, G.B. 2009, Research implementation and quality assurance project plan; An evaluation of hyperspectral remote sensing technologies for the detection of fugitive contamination at selected Superfund hazardous waste sites: U.S. Geological Survey Open-File Report 2009-1048, 18 p., at http://pubs.usgs.gov/of/2009/1048/.

Slonecker, E.T., and Fisher, G.B., 2011, An evaluation of traditional and emerging remote sensing technologies for the detection of fugitive contamination at selected Superfund hazardous waste sites: U.S. Geological Survey Open-File Report 2011-1050, 16 p., at http://pubs.usgs.gov/of/2011/1050/.

Slonecker, E.T., and Fisher, G.B., 2014, An evaluation of remote sensing technologies for the detection of fugitive contamination at selected Superfund hazardous waste sites in Pennsylvania: U.S. Geological Survey Open-File Report 2014-1081, 23 p., at http://pubs.usgs.gov/of/2014/1081/. 
Stevenson, B., O'Connor, R., Kendall, W., Stocker, A., Schaff, W., Alexa, D., Salvador, J., Eismann, M., Barnard, K., and Kershenstein, J., 2005, Design and performance of the Civil Air Patrol ARCHER hyperspectral processing system, in Defense and Security: International Society for Optics and Photonics, p. 731-742. (Also available at http://dx.doi.org/10.1117/12.604471.)

Swayze, G.A., Smith, K.S., Clark, R.N., Sutley, S.J., Pearson, R.M., Vance, J.S., and Roth, S., 2000, Using imaging spectroscopy to map acidic mine waste: Environmental Science \& Technology, v. 34, no. 1 , p. 47-54.

Tetra Tech, 2013, Final Phase II Environmental Site Assessment Report, Tampa-Clearwater Brownfield Site Survey TBA, 22nd Street Mixed Use Site, Tampa, Hillsborough County, Florida, EPA Contract No. EP-W-05-054 (START III, Region 4), Technical Direction Document No. TTEMI-05-003-0164: U.S. Environmental Protection Agency, 15 p.

Texas Commission on Environmental Quality, 2006, State risk-based screening values, Excel spreadsheet, accessed May 19, 2014, at http://www.tceq.texas.gov/assets/public/remediation/rrr/msc-rbscn_2006.xls.

Thenkabail, P.S., Smith, R.B., and De Pauw, E., 2000, Hyperspectral vegetation indices and their relationships with agricultural crop characteristics: Remote Sensing of Environment, v. 71, no. 2, p. $158-182$.

U.S. Environmental Protection Agency (EPA), 2007, Limited investigation led to missed contamination at Ringwood Superfund Site: EPA, Office of Inspector General, Evaluation Report No. 2007-P-00039, September 25, 2007.

U.S. Environmental Protection Agency (EPA), 2010, OSWER Cross-Program Revitalization Measures: EPA, Office of Solid Waste and Emergency Response, EPA-560-R-10001, 21 p.

U.S. Environmental Protection Agency (EPA), EPA Region 3, 2013, Mid-Atlantic Risk Assessment, generic tables, risk-based concentration tables, at http://www.epa.gov/reg3hwmd/risk/human/rbconcentration_table/Generic_Tables/index.htm.

Vane, G., and Goetz, A.F.H., 1988, Terrestrial imaging spectroscopy: Remote Sensing of Environment, v. 24, no. 1, p. 1-29.

Wu, Y., Chen, J., Ji, J., Gong, P., Liao, Q., Tian, Q., and Ma, H., 2007, A mechanism study of reflectance spectroscopy for investigating heavy metals in soils: Soil Science Society of America Journal, v. 71, no. 3, p. 918-926.

Zinnert, J.C., Via, S.M., and Young, D.R., 2012, Distinguishing natural from anthropogenic stress in plants; Physiology, fluorescence and hyperspectral reflectance: SpringerLink, v. 366, nos. 1-2, p. 133-141. 
